\title{
The interaction of compositional semantics and event semantics
}

\author{
Lucas Champollion
}

Published online: 23 December 2014

(C) The Author(s) 2014. This article is published with open access at Springerlink.com

\begin{abstract}
Davidsonian event semantics is often taken to form an unhappy marriage with compositional semantics. For example, it has been claimed to be problematic for semantic accounts of quantification (Beaver and Condoravdi, in: Aloni et al. (eds.) Proceedings of the 16th Amsterdam Colloquium, 2007), for classical accounts of negation (Krifka, in: Bartsch et al. (eds.) Semantics and contextual expression, 1989), and for intersective accounts of verbal coordination (Lasersohn, in Plurality, conjunction and events, 1995). This paper shows that none of this is the case, once we abandon the idea that the event variable is bound at sentence level, and assume instead that verbs denote existential quantifiers over events. Quantificational arguments can then be given a semantic account, negation can be treated classically, and coordination can be modeled as intersection. The framework presented here is a natural choice for researchers and fieldworkers who wish to sketch a semantic analysis of a language without being forced to make commitments about the hierarchical order of arguments, the argument-adjunct distinction, the default scope of quantifiers, or the nature of negation and coordination.
\end{abstract}

Electronic supplementary material The online version of this article (doi:10.1007/s10988-014-9162-8) contains supplementary material, which is available to authorized users.

\begin{abstract}
A 30-minute video of a talk that summarizes and complements this paper is available at https://www. youtube.com/watch? $\mathrm{v}=21 \mathrm{KxSsIceNg}$ and has been posted as a supplemental material to this paper, available at http://dx.doi.org/10.1007/s10988-014-9162-8. The video walks through the derivations in the paper by using the Lambda Calculator (Champollion et al. 2007). This software application has also been used to check the derivations for correctness and to generate the figures in this paper. Information on the calculator, as well as a basic version of the tool, is available at http://www.lambdacalculator.com. Please contact me via email at champoll@gmail.com for a more advanced version of the calculator, along with a file that implements the formal system and derivations presented here.
\end{abstract}

L. Champollion ( $\square)$

Department of Linguistics, NYU, New York, NY, USA

e-mail: champoll@gmail.com 
Keywords Event semantics - Thematic roles · Quantifiers · Negation · Coordination · Conjunction $\cdot$ For-adverbials

\section{Introduction}

Ever since Montague famously rejected the contention that there is any important theoretical difference between formal and natural languages, research on compositional semantics in his spirit has produced successful accounts of the behavior of scope-taking expressions (Montague 1970). In particular, those expressions in natural language that have counterparts in predicate logic and related systems, such as quantifiers, negation, and conjunctions, have been given formal accounts. It has turned out in many cases that these counterparts, or suitable generalizations, are viable candidates for the formal representations of the core semantic meanings, and in particular of the scopal properties, of the relevant natural-language expressions. This can be seen, for example, in accounts of quantificational noun phrases in terms of generalized quantifiers (Barwise and Cooper 1981), in accounts of truth-functional linguistic negation in terms of logical negation (Horn 1989) and in accounts of coordination in terms of generalized logical conjunction and disjunction (Partee and Rooth 1983). This is perhaps not surprising given that, historically speaking, the design of predicate logic was inspired by natural language.

Another successful tradition in semantics stems from Davidson's proposal that the logical form of action sentences makes reference to underlying events (Davidson 1967). Building on this idea, semantic research has developed successful accounts of a large number of phenomena such as verbal modification, the relations between adjectives and adverbs, the relations between nominalizations, nominal gerunds, and verbs, the semantics of perception verbs, and the semantic relations between related members of semantic alternations such as causatives and inchoatives (Parsons 1990, 1995).

I will call the two frameworks just mentioned "compositional semantics" and "event semantics". For the purpose of this paper, I take the advantages of each of these two frameworks to have been firmly established. The natural next question to ask is what is the best way to combine the two. This question is relevant for at least two kinds of addressees.

- The theoretical researcher may be primarily interested in interactions, such as whether a commitment to events implies or suggests a commitment to this or that analysis of a scope-taking expression - say, whether events require an analysis of quantifiers in syntactic terms and a commitment to a representational level distinct from surface form. I will argue that it does not, and I will present similar kinds of results in the case of analyses of negation and coordination.

- The student and the semantic fieldworker who wish to sketch an analysis of a language without making implicit semantic commitments about the difference between arguments and adjuncts may want to adopt event semantics because it provides the ability to treat them on par. They may also be interested in giving standard analyses of such commonplace phenomena as quantifiers and negation.

There is currently no consensus on what is the best way to combine compositional semantics and event semantics, whether it is possible or easy, and what consequences 
the presence of events has on the analyses of scope-taking expressions in compositional semantics. In many implementations of event semantics in compositional frameworks, accounts of scope-taking expressions such as quantifiers, negation, and conjunctions need to be complicated compared with the more standard treatments that would be available if events were not present. Perhaps for this reason, textbooks of compositional semantics tend to avoid using events (Heim and Kratzer 1998). An aspiring semanticist or a fieldworker might be discouraged by this situation, particularly when a given language or phenomenon that seems to be well-suited to event semantics also involves scope-taking expressions that need to be analyzed in some way.

This paper aims to remedy this situation by presenting an implementation of event semantics that combines with standard treatments of scope-taking expressions in a well-behaved way. I will call this implementation "quantificational event semantics". The implementation is then used to show that event semantics is compatible with the standard accounts of scope-taking expressions that have been developed in the tradition of Montague, and that the presence of events does not make it necessary to choose between accounts of these expressions in the way it has been claimed.

For example, there has been a long debate on whether the scope of quantificational arguments is determined syntactically, for example by quantifier raising (May 1985), or semantically, for example by type-shifting (Hendriks 1993). It has been claimed more recently that adopting event semantics bears on this choice in a way that is not seen as advantageous. Thus, Beaver and Condoravdi (2007) hold that "[i]n Davidsonian Event Semantics the analysis of quantification is problematic: either quantifiers are treated externally to the event system and quantified in (Landman 2000), or else the definitions of the quantifiers must be greatly (and non-uniformly) complicated (cf. Krifka 1989)". They suggest as an alternative a nonstandard framework in which verbal denotations hold of partial functions that map designated constants like "agent" and "theme" to individuals. For related criticism and similar proposals, see Eckardt (2010) and Winter and Zwarts (2011). I take Beaver and Condoravdi (2007) as a representative example of these proposals (though there are important differences between them) and I discuss it in Sect. 5.

Contrary to such claims, I argue that the analysis of quantifier scope does not pose any special problems in an event semantic framework. That is, adopting one or the other view on quantifier scope does not entail a commitment on whether events are present in the system. For semanticists who reject quantifying-in or quantifier raising as an option, such as Beaver \& Condoravdi and Eckardt, it is possible to adopt a semantic approach to quantifier scope in a completely standard event-based framework. Conversely, adopting one or the other view on the presence of events does not force the semanticist to take a stance on whether quantifier scope is determined syntactically or semantically. Schematically, my strategy consists in filling a corner in the 2-by-2 matrix that is opened by the parameters mentioned above (see Table 1).

The main technical innovation in this paper will consist in abandoning the idea that the event variable is bound at sentence level, as is generally assumed in compositional approaches to event semantics. Instead, I will assume that verbs and their projections (such as verb phrases and sentence radicals) denote existential quantifiers over events. As we will see, this move is motivated by the fact that the event quantifier always takes lowest possible scope, and it will turn out to give us additional degrees of freedom that 
Table 1 Analyses of quantification and events

\begin{tabular}{lll}
\hline & No events & Events \\
\hline Syntactic account & e.g. May (1985) & e.g. Landman (2000) \\
Semantic account & e.g. Hendriks (1993) & This paper \\
\hline
\end{tabular}

we can exploit in order to give a semantic account of quantifier scope. Later on we will see that the same move also makes it possible to adopt accounts of negation and conjunction in which their denotations mirror those of their counterparts in predicate $\operatorname{logic}(\neg$ and $\wedge)$.

This paper does not present in detail syntactic approaches to quantifier scope, since they can be extended to event semantic frameworks straightforwardly; see Landman (1996, 2000) for an overview. However, let me briefly mention why syntactic approaches have been considered problematic. In these approaches, type mismatches between verbs and quantificational arguments are resolved by movement. This is sometimes perceived as cumbersome. As Eckardt (2010) observes, "the semantic composition of even a simple sentence like John likes most Fellini movies requires quantifier raising, interpreted traces, coindexing, and lambda abstraction." Since syntactic approaches rely on covert movement, they entail the presence of a representational level (Logical Form) that is distinct from the surface level. As such, they are not directly compositional (Jacobson 1999; Barker 2002). Finally, there is an overgeneration worry: In languages and configurations where surface scope determines semantic scope (see e.g. Beghelli and Stowell 1997 for English, and C.-T. J. Huang 1999; S.-F. Huang 1981 for Chinese), nothing short of additional assumptions ensures that raised quantifiers keep their relative order the same as before they raised.

Two caveats before we begin. First, the nonstandard systems in the papers cited above are motivated not only by the representation of quantificational arguments but also by additional considerations, such as the representation of stacked temporal modifiers as in On most days, it rained in the afternoon (Beaver and Condoravdi 2007) and the ability to make all arguments of a verb semantically accessible at any point in the derivation (Eckardt 2010). Second, I do not consider scopeless readings of quantifiers, such as cumulative and collective quantification as in Twenty composers collaborated on seven shows (Schein 2002). These readings increase the complexity of both eventbased and eventless grammars because it is not possible to derive these readings by giving one quantifier scope over the other. My omission is justified because the claims by Beaver \& Condoravdi and Eckardt about the difficulty of integrating quantifier scope and event semantics are not based on these complex cases. In principle the present account can be combined with mereology-based analyses of scopeless readings of increasing quantifiers, along the lines of Krifka (1989) and Landman (2000). As for scopeless readings of non-increasing quantifiers, the compatibility question is open; for relevant discussion see Schein (1993), Krifka (1999) and Brasoveanu (2012).

The rest of the paper is organized as follows. I first show in Sect. 2 that the existential quantifier that binds the event variable always takes lowest possible scope. I suggest that this is because it is contained in the lexical entry of the verb, rather than being introduced at sentence level. I show that in the presence of type shifting rules, event se- 
mantics does not require a commitment to a representational level distinct from surface form as far as quantifiers are concerned. I then show in Sect. 3 that fixed-scope operators like negation and modals can be given a straightforward and standard treatment, and that in particular event semantics does not make it necessary to resort to a non-standard account of negation in terms of mereological fusion as claimed by Krifka (1989). Section 4 shows that coordination can be given a standard intersective denotation in the present framework, and critically reviews a claim to the effect that event semantics favors a collective account of coordination (Lasersohn 1995). Section 5 discusses the eventless system by Beaver and Condoravdi (2007) and shows that most aspects of that system can be reproduced in the present framework. Section 6 concludes.

\section{Quantification in a Neo-Davidsonian framework}

The difference between syntactic and semantic approaches to quantifier scope is traditionally studied in classical Montagovian semantic systems, where verbs are translated as n-ary relations that hold between their arguments. Such a translation draws a firm semantic distinction between (obligatory) arguments and (optional) adjuncts. Expressions in which some arguments are missing, like kiss Mary or John kissed, are not assigned a truth value. Among alternatives that treat arguments and adjuncts on a par, the best-known one is the Neo-Davidsonian approach (Parsons 1990). In a typical instantiation, verbs and all their projections up to the sentence level are translated as predicates of events, and verbal arguments modify events via thematic roles like agent and theme. Variations of this setup are found, for example, in Carlson (1984), Krifka (1989), Parsons (1995) and Landman (2000). At the sentence level, a silent operator (called sentence mood operator in Krifka (1989) or more commonly existential closure) then binds the event argument, typically with an existential quantifier. Some syntactic mechanism (e.g. the theta criterion) is assumed to make sure that the operator can only apply once all the syntactic arguments of the verb have been introduced to the derivation, and not earlier. For example, a sentence like John kissed Mary is translated as follows, disregarding tense:

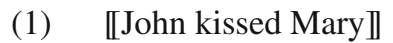

$$
=\exists e \cdot \operatorname{kiss}(e) \wedge \mathbf{a g}(e, \mathbf{j o h n}) \wedge \operatorname{th}(e, \operatorname{mary})
$$

Neo-Davidsonian approaches to event semantics make no difference between arguments and adjuncts. They rely on syntactic devices, for example on the theta criterion, to label subjectless sentences like kiss Mary as ungrammatical; as far as meaning is concerned, they could assign such expressions a truth value, in this case, $\exists e . \operatorname{kiss}(e) \wedge \mathbf{t h}(e, \mathbf{m a r y})$. The difference between such expressions and full sentences is determined by syntax, not by semantics. The specific approach I will adopt is also Neo-Davidsonian, but many of the problems I will point out with existing NeoDavidsonian approaches are shared by classical Davidsonian systems in which a verb like kiss is represented as a three-place relation between a kisser, a kissee, and a kissing event. To a large extent, although I will not demonstrate it, the general principles of the solution that I will adopt carry over to classical Davidsonian treatments, because these principles do not rely in any crucial way on the assumption that the argument- 
adjunct distinction either is or is not represented in the semantics. Essentially, I will adapt type-shifting techniques originally developed for eventless verbal denotations by Hendriks (1993). These techniques can be adapted to the classical Davidsonian case with slight modifications and to the Neo-Davidsonian case with larger modifications. I will demonstrate only the Neo-Davidsonian case.

When a verbal argument is itself quantificational, it needs to take scope above this event quantifier. This is a well-known fact and it is reflected in many Neo-Davidsonian theories. For example, the Scope Domain Principle in Landman (1996) states that only nonquantificational noun phrases can be "entered into scope domains". In the context of Landman's theory, where "scope domain" means "verbal denotation", this principle in effect says that only nonquantificational noun phrases can be interpreted in situ, and it has the consequence that all quantificational noun phrases must take scope over the event argument. For example, the correct translation of John kissed every girl according to the Scope Domain Principle is (2). This represents the fact that the sentence entails that for every girl, there is a separate event in which John kissed that girl. For example, the sentence John kissed Mary is represented as (3). It follows logically from (2) given the additional assumption that Mary is a girl (4).

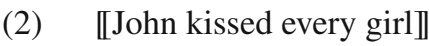

$$
=\forall x[\operatorname{girl}(x) \rightarrow \exists e[\operatorname{kiss}(e) \wedge \operatorname{ag}(e, \mathbf{j o h n}) \wedge \operatorname{th}(e, x)]]
$$

(3) «John kissed Mary

$$
=\exists e[\mathbf{k i s s}(e) \wedge \mathbf{a g}(e, \mathbf{j o h n}) \wedge \operatorname{th}(e, \operatorname{mary})]
$$

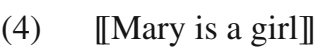

$$
=\operatorname{girl}(\operatorname{mary})
$$

The alternative translation in which the event quantifier takes wide scope, (5), expresses that there is a single event which was an event of John kissing every girl. This contradicts not only the Scope Domain Principle and related assumptions, but also our intuitions about kissing, since we think of different kissings as different events and these events are not represented. The following translation therefore does not seem to represent any reading of the sentence.

$$
\begin{aligned}
& \text { [John kissed every girl } \rrbracket(\text { problematic translation) } \\
& =\exists e[\mathbf{k i s s}(e) \wedge \mathbf{a g}(e, \mathbf{j o h n}) \wedge \forall x[\operatorname{girl}(x) \rightarrow \operatorname{th}(e, x)]]
\end{aligned}
$$

The translation is problematic, not because it makes available a single event, but because it does not make the individual kissing events available. This is not to deny that a single (complex) might be ultimately needed. The sentence might be true even if the individual kissings only took a second. It is possible to follow it up with It took very long, as a reviewer notes. This suggests that the representation needs to provide a complex event that might be thought of as the fusion of all the distinct kissing events. The anaphoric variable it can then refer back to that complex event. Other arguments for this kind of complex events are provided by Schein (1993) and Kratzer (2000) on the basis of cumulative readings of sentences like Three copy editors caught every mistake in the manuscript. For a summary and a critical discussion of these arguments, see Champollion (2010a). Here I focus on the individual events that correspond to the 
separate kissings. I come back to fusion events in Sect. 3. The end of Sect. 5 sketches an extension of the present account to intersentential anaphora that is laid out in more detail in Champollion (to appear-a).

In general, the event quantifier always takes lowest possible scope with respect to other scope-taking elements. For example, sentence (6) only has the reading (7a) and cannot mean (7b). While (7b) might be ruled out for independent reasons (for example because almost every event will trivially make it true), the fact remains that the quantifier no boy must be able to take wide scope with respect to the event quantifier in order to derive the reading (7a). Even with respect to fixed-scope operators like negation, the event quantifier always seems to take low scope (8).

(6) No boy laughed.
a. $\neg \exists x[\operatorname{boy}(x) \wedge \exists e[\operatorname{laugh}(e) \wedge \mathbf{a g}(e)=x]]$ $\neg \exists x \gg \exists e$
"There is no laughing event that is done by a boy."
b. $\exists e[\neg \exists x[\operatorname{boy}(x) \wedge \operatorname{laugh}(e) \wedge \operatorname{ag}(e)=x]]$
$* \exists e \gg \neg \exists x$
"There is an event that is not a laughing by a boy."

(8) John didn't laugh.
a. $\neg \exists e[\operatorname{laugh}(e) \wedge \mathbf{a g}(e)=\mathbf{j o h n}]$
$\neg \gg \exists e$
"There is no event in which John laughs."
b. $\exists e \neg[\operatorname{laugh}(e) \wedge \mathbf{a g}(e)=\mathbf{j o h n}]$
"There is an event in which John does not laugh."

An additional reason for giving low scope to the event quantifier is more theoryinternal: Many Neo-Davidsonian frameworks assume that thematic roles are functions (the Unique Role Requirement, Carlson 1984; Parsons 1990; Landman 1996, 2000). This has the effect of making the wrong translation (5) a contradiction in all models in which there is more than one girl, since the Unique Role Requirement entails that no more than one girl can be the theme of a kissing event. The analysis to be developed here can accommodate the Unique Role Requirement. For clarity, I will represent thematic roles using functional notation from now on, e.g. "th $(e)=x$ " instead of "th $(e, x)$ ".

As described above, typical instantiations of the Neo-Davidsonian framework apply existential closure to the event quantifier at sentence level (e.g. Krifka 1989; Parsons 1995; Landman 1996). Therefore, any theory of quantifier scope needs to give all argument quantifiers the ability to take scope above the sentence level to derive the correct truth conditions. [Some instantiations apply existential closure at the VP level, and regard subjects as outside the VP, e.g. Carlson (2003) following Diesing (1992). In this case, only argument quantifiers within the VP, such as the object quantifier, need to be given the ability to take scope above VP level in order to derive the correct truth conditions.] It is here that a difference between syntactic and semantic theories of quantifier scope arises.

For syntactic theories such as May's Quantifier Raising (QR), it is no problem to raise a quantifier above sentence level; this is in fact their normal operating mode. This is illustrated in Fig. 1. For convenience, I have followed Landman (1996, 2000) in placing the thematic roles directly into the verb meaning, but this is not crucial. 


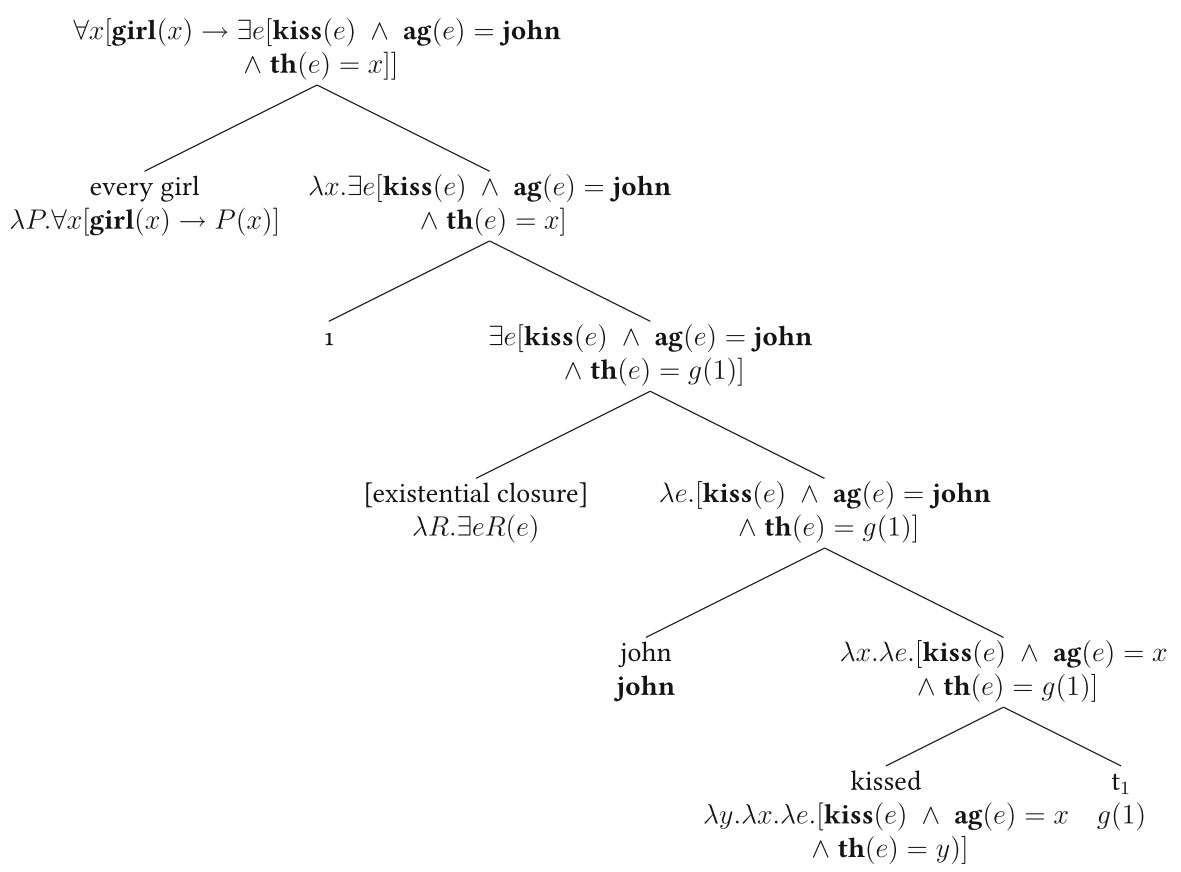

Fig. 1 "John kissed every girl" in an event framework, using quantifier raising

By contrast, many semantic theories are designed to allow quantifiers to be interpreted in situ. Some examples are the argument raising rule of Hendriks (1993), the type-shifting rule for quantifiers presented in the textbook by Heim and Kratzer (1998), and the continuation passing style transforms used in Barker (2002). Many such theories amount to lifting the type of the verb or verbal projection so that it expects a quantifier instead of an individual-type argument. In case a verb combines with multiple quantifiers, its type can be lifted several times. The order in which these lifting operations are applied to the verb determines the scope of its arguments. For example, in Hendriks' system, the order in which the argument raising rule is applied to a transitive verb determines the scope that its quantificational arguments take towards each other.

In the Neo-Davidsonian framework described above, the event quantifier is introduced by existential closure after any other quantifiers, but it always has to take scope under all of them. In a Hendriks-style system, this requires that every verb be typelifted for the event quantifier that comes in the guise of existential closure. But since every sentence contains this event quantifier, one might then as well rewrite lexical entries of verbs to incorporate the existential closure over their event argument.

This leads me to the main technical innovation and the central claim of this paper. I propose that verbs are not interpreted as predicates of events (10), but as predicates that hold of sets of events (11). Conceptualizing Neo-Davidsonian event semantics this way requires a shift in thinking. Instead of denoting the set of all raining events, 
think of a predicate like "rain" as being true of any set that contains a raining event. I let the variable $f$ range over event predicates.

(10) Previous (Neo-Davidsonian) approaches to event semantics:

$$
\llbracket \operatorname{rain} \rrbracket=\lambda e[\operatorname{rain}(e)]
$$

(11) This approach:

$$
\llbracket \text { rain }=\lambda f \exists e[\operatorname{rain}(e) \wedge f(e)]
$$

On the new view, which I will refer to as quantificational event semantics, a verb will be true of any set of events $f$ so long as $f$ contains (possibly among other things) an event that satisfies the relevant event predicate.

Assuming that the verb rain does not take any semantically visible arguments, and ignoring tense and aspect for now, the truth conditions of a sentence like it is raining can be obtained by checking whether the set of all events whatsoever, $\lambda$ e.true, has the property denoted by the verb. The meaning of it is raining comes out as follows:

$$
\begin{aligned}
& \text { 【It is raining】 } \\
& \text { a. }=\lambda f \exists e[\operatorname{rain}(e) \wedge f(e)](\lambda e \text {.true }) \\
& \text { b. }=\exists e[\operatorname{rain}(e) \wedge(\lambda e \cdot \operatorname{true})(e)] \\
& \text { c. }=\exists e[\operatorname{rain}(e) \wedge \text { true }] \\
& \text { d. }=\exists e[\operatorname{rain}(e)]
\end{aligned}
$$

Since this proposal is the core of this paper, let me restate the motivation for this move to the extent that I have presented it so far, and provide some explanation of the intuition behind this idea. There is a conceptual difference between the quantifiers that are used to capture the semantic behavior of quantificational noun phrases and the existential quantifier that binds the event variable. The former not only capture the semantics of quantificational noun phrases but also their scopal ambiguity in languages like English. The various ways to arrange quantifiers in logical formulas correspond to the differences in meaning between readings of scopally ambiguous sentences like $A$ diplomat visited every country. The latter captures the indefinite nature of events. But here there is no counterpart to the scopal ambiguity of quantificational noun phrases. As we have seen above, event quantifiers always take lowest possible scope. In this respect they are arguably less like ordinary quantificational arguments and more like bare plurals (see Dayal 2011 for a recent overview). The simplest way to model this fact compositionally is to introduce the event quantifier at the place where it is observed to occur, namely as low as possible. Putting existential closure into the lexical entry of the verb will automatically derive the fact that all other quantifiers always have to take scope above existential closure. This move is reminiscent of the way Carlson (1977) puts existential quantification over stages into the lexical semantics of stage-level predicates, thereby ensuring that bare plurals can denote kinds and their existential import takes narrowest scope.

The entry in (11) can be derived from the one in (10) by the type-shifting principle $A$ in Partee (1987), but this parallel should be taken with a grain of salt. Type shifting is generally understood to occur "online" during the computation of the meaning of a sentence, while quantificational event semantics, the present proposal, applies it 
"offline" in the lexicon. The move from (10) to (11) is better understood as an operation that rewrites an entire grammar, similarly to the continuization procedure in Barker (2002).

We will let not only verbs but all their projections hold of sets of events. For example, we can think of a verb phrase like "see Mary" as being true of any set that contains a seeing event whose theme is Mary.

$$
\llbracket \text { see Mary } \rrbracket=\lambda f \exists e[\operatorname{see}(e) \wedge f(e) \wedge \operatorname{th}(e)=\operatorname{mary}]
$$

Changing the type of verbs and verbal projections from sets of events to sets of sets of events paves the way for a number of theoretical moves, and the rest of this paper is devoted to them. For example, quantificational event semantics gives us a handle on interpreting quantifiers in situ. On the old approach, a verb phrase had to be true of an event, so it was not clear what kind of event a verb phrase like "kiss every girl" could be true of. Now that verb phrases hold of sets of events, we can formulate the meaning of verb phrases containing quantifiers in an intuitive way: "kiss every girl" is true of any set of events that contains a potentially different kissing event for every girl.

$$
\begin{aligned}
& \llbracket \text { kiss every girl } \rrbracket \\
& =\lambda f \forall x[\operatorname{girl}(x) \rightarrow \exists e[\operatorname{kiss}(e) \wedge f(e) \wedge \operatorname{th}(e)=x]]
\end{aligned}
$$

For simple declarative sentences, we still need a sentence-level operator, but it has a function somewhat different from existential closure: It asserts that the predicate is true of the set of all events. Intuitively, one might think of the world as the set of all events that exist. Then, the sentence-level operator asserts that the sentence is true of the world. As usual, I assume that syntax is responsible for making sure that the operator only applies once all the syntactic arguments of the verb have been introduced.

$$
\llbracket[\text { closure }] \rrbracket=\lambda e . \text { true }
$$

This simple picture can be refined by restricting the set of events denoted by the closure operator in various ways, and/or by introducing additional operators. For example, if we believe that certain sentences involve definite rather than indefinite reference, say to a particular event $e_{0}$, we could supply this by a definite closure operator with the meaning $\lambda e . e=e_{0}$. Or, we may wish to add projections for tense, aspect, perfect, etc. above the event level, in the style of Iatridou et al. (2001). I will not spell out these refinements here, but Sect. 3 has an implementation of a simple treatment of tense.

This closure operator is similar to the downarrow operator of Dynamic Montague Grammar, which maps the dynamic interpretation of a sentence to a truth value (Groenendijk and Stokhof 1990), and to the Lower operator of Barker and Shan (2008), which does the same for a continuized interpretation by applying it to a trivial continuation. All these type shifters are used to similar effect in their respective systems: They strip away the layers of complexity introduced by the semantic machinery and map a predicate to what are intuitively its truth conditions.

I treat noun phrases as generalized quantifiers over individuals (type $\langle e t, t\rangle$ ). This part of the analysis is completely standard. I use $P$ for predicates of individuals (type $\langle e t\rangle)$ : 


$$
\begin{aligned}
& \llbracket \text { every girl } \rrbracket=\lambda P \forall x[\operatorname{girl}(x) \rightarrow P(x)] \\
& \llbracket \text { a diplomat } \rrbracket=\lambda P \exists x[\operatorname{diplomat}(x) \wedge P(x)]
\end{aligned}
$$

Thematic roles can be introduced either as part of the verbal denotation or through other means. For concreteness, I assume that they are provided by separate syntactic heads that combine noun phrases with verbal projections and provide the necessary semantic type-lifting. In particular, a thematic role head like theme combines a quantificational noun phrase with the denotation of a verbal projection, which is a generalized quantifier over events, and returns another generalized quantifier over events. This ensures that all verbal projections have the same type, namely $\langle v t, t\rangle$, where $v$ stands for the type of events. Here is the denotation of such a thematic role head (I use $V$ for predicates of type $\langle v t, t\rangle$, and $Q$ for predicates of type $\langle e t, t\rangle)$. Prepositions can follow exactly the same scheme:

$$
\llbracket[\operatorname{th}] \rrbracket=\lambda Q \lambda V \lambda f[Q(\lambda x[V(\lambda e[f(e) \wedge \operatorname{th}(e)=x])])]
$$

After this head combines with a quantificational noun phrase such as the one in (16), the resulting constituent is of type $\langle\langle v t, t\rangle,\langle v t, t\rangle\rangle$.

Under these assumptions, we can derive the meaning of a sentence like John kissed every girl in a variable-free manner, without the application of movement or traces, and with function application as the only operation. This is shown in Fig. 2 for John kissed every girl. Compare this with Fig. 1, where movement, trace interpretation, and lambda abstraction have been used for the same sentence.

The framework can be extended in different ways to derive quantifier scope ambiguities. For example, this could be done as in Hendriks (1993) by argument raising, or as in Beaver and Condoravdi (2007) by applying arguments to the verb in different orders. Another possibility is to lift the type of the thematic role heads, as shown in Figs. 3 and 4. These figures show the surface and inverse scope readings of A diplomat visited every country respectively. The only difference between them is that the thematic role head [th] in the former has been replaced by [th-lift] in the latter. This results in inverse scope. We can capture the difference between languages in which surface order determines semantic scope and languages in which scopal order is free by adding or removing type-lifted thematic role heads like [th-lift] in Fig. 4 from the lexicon. If one wants to generalize the system to the case where we have more than two quantifiers, and if one desires to avoid redundancy, one may want to formulate an operator that generates [th-lift] and other heads from [th] by a version of Hendriks' argument raising. This would have to be made available on a per-language basis, as opposed to being a theorem of the system.

The present framework can also be extended to deal with the distributive-collective ambiguity. While distributivity is a complex topic, the following sketch may serve as a proof of concept. A sentence like John invited four girls is ambiguous between a collective reading, in which a joint invitation was issued to the four girls as a whole, and a distributive reading, in which each of the girls received a separate invitation. The classical example The boys lifted the piano is similar: either there was just one pianolifting or as many piano-liftings as there were boys. It is natural to model invitations and liftings as events, so the difference between the two readings, at least in the cases 


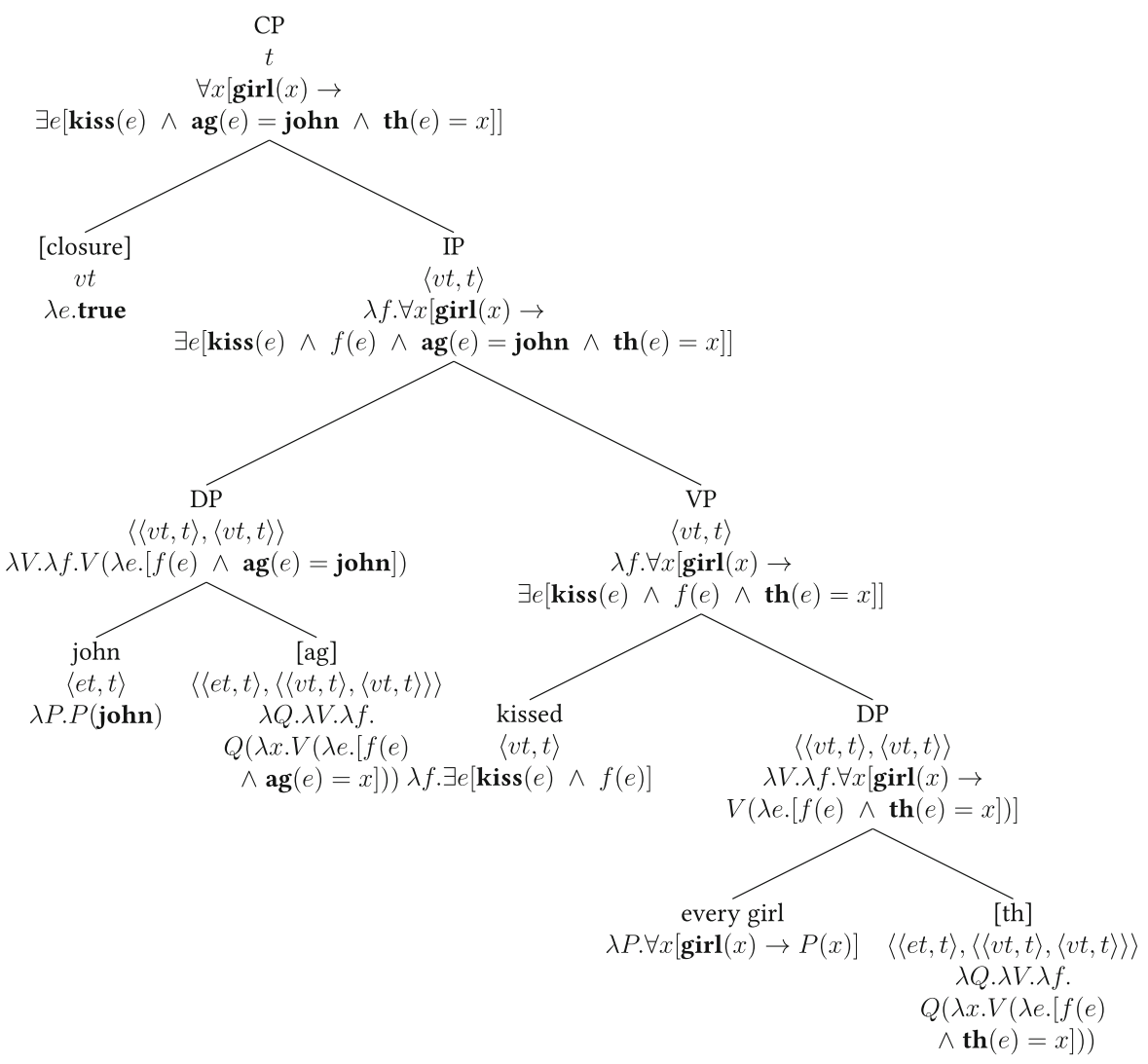

Fig. 2 Basic illustration of the present framework, using the sentence "John kissed every girl"

at hand, can be modeled in this way (Landman 2000). We may assume that verbs like invite can have groups of individuals as well as individuals as themes. We can model groups as sets or as mereological fusions (Link 1998). If we model groups as sets, the two readings can be represented as follows:

(19) John invited four girls.

a. $\exists X \subseteq$ girl. $|X|=4 \wedge \exists e$.invite $(e) \wedge \operatorname{ag}(e)=\mathbf{j o h n} \wedge \operatorname{th}(e)=X]$

b. $\exists X \subseteq$ girl. $|X|=4 \wedge \forall y . y \in X \rightarrow[\exists e . \operatorname{invite}(e) \wedge \operatorname{ag}(e)=$ john $\wedge \operatorname{th}(e)=y]$

It has been suggested that this ambiguity is due to whether the numeral four girls undergoes an ordinary or a distributive, scopal form of quantifying-in (Landman 2000). In the present system we do not have scopal quantifying-in at our disposal, but we can use a silent operator to simulate its effect. Assume that four girls has the basic denotation in (20), where $\alpha$ ranges over individuals (type $e$ ) and sets of individuals (type et). By substituting this denotation for every girl in Fig. 2 and replacing kiss by invite, we can derive the collective interpretation in (19a). The operator in (21) 


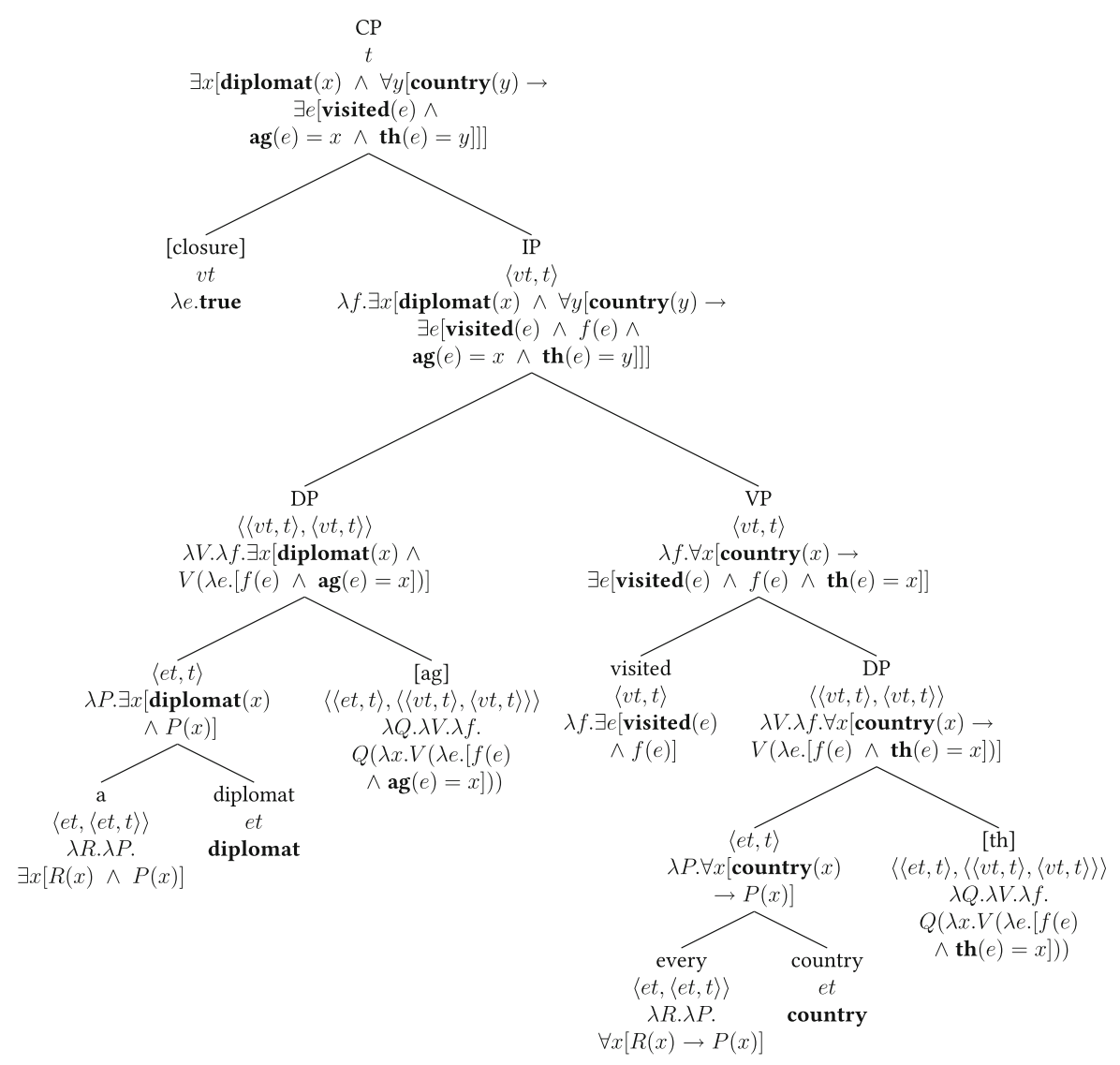

Fig. 3 A diplomat visited every country (surface scope)

shifts (20) to its distributive denotation in (22). This shifted denotation derives the distributive interpretation in (19b).

(20) $\llbracket$ four girls $\rrbracket=\lambda P_{\langle\alpha t\rangle} \cdot \exists X \subseteq$ girl. $|X|=4 \wedge P(X)$

(21) $\llbracket[$ dist-shift $] \rrbracket=\lambda Q_{\langle e t, t\rangle} \lambda P_{\langle e t\rangle} \cdot Q(\lambda X . \forall y . y \in X \rightarrow P(y))$

$$
\llbracket(21) \rrbracket(\llbracket(20) \rrbracket)=\lambda P_{\langle e t\rangle} . \exists X \subseteq \text { girl. }|X|=4 \wedge \forall y \cdot y \in X \rightarrow P(y)
$$

There is much more to say about distributivity than I can do here. An overview of some of the relevant facts and proposals can be found in Champollion (to appear-b) and the references there. For more elaborate theories of distributivity in event semantics that implements a translation of the D operator known from Link (1991, 1998), see Lasersohn (1995) and Champollion (2014a,b). The interaction of some of these theories with the present framework is discussed in Schwarzschild (2014) and Champollion (2014c).

Let me summarize this section. I have provided a way to combine Neo-Davidsonian event semantics with a semantic account of quantifier scope along the lines of Hen- 


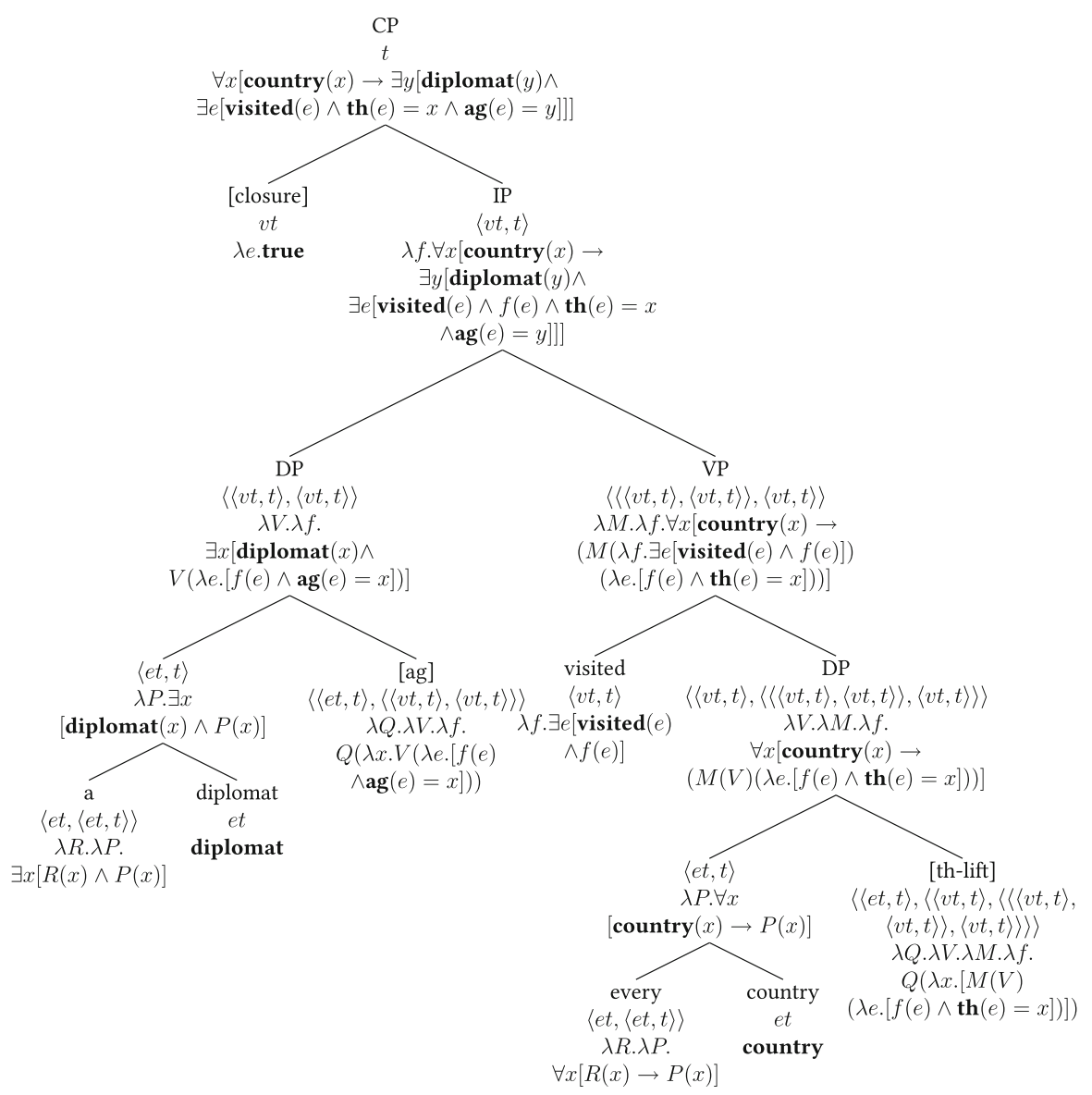

Fig. 4 A diplomat visited every country (inverse scope)

driks (1993). Based on the observation that the event quantifier always takes low scope, I have included it into the lexical entry of the verb. This not only derives the scope observation but also allows us to give directly compositional (non-assignmentdependent) meanings to verbal projections that contain quantifiers, such as kiss every girl. To be clear, this is an independence result, not an argument against a particular theory of quantifier raising. There is no claim here that semantic approaches to quantifier raising are inherently superior to syntactic approaches. Many phenomena involving quantification can be given syntactic as well as semantic accounts. Compare for example the QR-based, syntactic account of subject/object asymmetries involving antecedent-contained deletion in Hackl et al. (2012) with the type-shifting-based, semantic account of these asymmetries in Szabolcsi (2014). Rather, the claim is simply that event semantics is compatible with both syntactic and semantic approaches and that the choice between them does not depend on a decision to adopt events. 


\section{Negation}

In the system presented here, all verbal arguments and modifiers, no matter what their syntactic category is, uniformly have the same semantic type, namely $\langle\langle v t, t\rangle,\langle v t, t\rangle\rangle$. This applies in particular to scope-taking operators like negation and modals. In this section, I sketch an analysis of these operators, concentrating on negation. I compare the resulting treatment of negation to the fusion-based system in Krifka (1989).

Just like quantification, negation has been considered particularly difficult for event semantics because it leads to apparent scope paradoxes (Krifka 1989). As observed by Smith (1975), for-adverbials like for two hours can take scope both above negation and below it. For example, (23) can be interpreted both as (23a) and as (23b):

John didn't laugh for two hours.

a. For two hours, it was not the case that John laughed.

b. It is not the case that John laughed for two hours.

We have seen above, in connection with examples like (6) and (8), that negation always seems to take scope above the event quantifier. This would mean that in order to lead to interpretations like (23a), the for-adverbial must be able to take scope above the event quantifier. If one assumes, as Krifka does, that the event quantifier is introduced at the sentential level via existential closure, this means that the for-adverbial must be able to take scope at the sentential level. Krifka considers this conclusion undesirable because of examples like the following, which he takes to show that for-adverbials cannot take scope over sentence adverbs like fortunately:

Krifka suggests that this can be explained if sentence adverbs apply to propositions (which he assumes are only available at sentence level) whereas durative adverbials cannot apply to propositions. For the sake of argument, let us adopt the spirit of this point of view and require of our framework that we must be able to interpret for-adverbials at verb phrase level. One certainly does not want to be forced by the choice of one's framework to take a position on the scope of for-adverbials, as there is currently no consensus on whether they attach below or above the subject. This issue is relevant in connection with the interaction of for-adverbials and the Perfect. See Rathert (2004) for a discussion of the relevant issues and literature.

Krifka himself resolves the apparent scope paradox by concluding that negation, after all, takes scope under and not over the event quantifier, contrary to what is suggested by the facts in (6) and (8). Given the background assumption that foradverbials do not take scope at the sentential level, this decision is necessary for Krifka in order to explain why for-adverbials take scope both above and below negation. But this decision requires translating negation in a nonstandard way. Krifka uses the mereological concept of fusion for this purpose. Simply put, the fusion of an event predicate is something which has the type of an event and which is obtained by merging all the events that satisfy the event predicate. For an overview of mereology, see Champollion and Krifka (to appear). "Fusion" refers to the same concept as what is called "sum" in that handbook article. 
Krifka translates did not as involving the fusion of all the events that take place within some time interval. For this purpose, Krifka introduces the notion of a maximal event of some time and defines it as below. In the following definition, I follow Krifka's notation. Specifically, $\tau$ stands for the "temporal trace" function that maps events to the time intervals at which they occur; $\subseteq_{T}$ denotes the subinterval relation between temporal intervals; $\subseteq_{E}$ denotes the mereological parthood relation that holds between the fusion event and its subevents; and $\operatorname{FuSION}_{E}$ refers to the fusion of a set of events.

\section{Definition: Maximal Event (Krifka 1989) \\ $\forall e . \operatorname{MXE}(e) \leftrightarrow \exists t\left[e=\operatorname{FusION}_{E}\left(\lambda e^{\prime}\left[\tau\left(e^{\prime}\right) \subseteq_{T} t\right]\right)\right]$}

(An event is maximal iff it is the sum of all the events whose runtimes are parts of a given temporal interval.)

Krifka then uses these maximal events as part of his definition of negation, which is as follows:

$$
\begin{aligned}
& \llbracket \text { did not } \rrbracket_{K r i f k a} \\
& =\lambda P \lambda e \exists t\left[\operatorname{MXE}(e) \wedge \neg \exists e^{\prime \prime}\left[P\left(e^{\prime \prime}\right) \wedge e^{\prime \prime} \leq e\right]\right] \\
& =\lambda P \lambda e \exists t\left[e=\operatorname{FuSION}_{E}\left(\lambda e^{\prime}\left[\tau\left(e^{\prime}\right) \subseteq_{T} t\right]\right) \wedge \neg \exists e^{\prime \prime}\left[P\left(e^{\prime \prime}\right) \wedge e^{\prime \prime} \subseteq_{E} e\right]\right]
\end{aligned}
$$

Based on this entry, Krifka translates a sentential event predicate like John didn't laugh as a predicate that is true of any fusion of events that all take place within some time, so long as none of them is an event of John's laughing:

$$
\begin{aligned}
& \llbracket \text { John did not laugh } \rrbracket= \\
& \exists e \exists t\left[e=\operatorname{FuSION}{ }_{E}\left(\lambda e^{\prime}\left[\tau\left(e^{\prime}\right) \subseteq_{T} t\right]\right)\right. \\
& \left.\wedge \neg \exists e^{\prime \prime}\left[e^{\prime \prime} \subseteq_{E} e \wedge \operatorname{laugh}\left(e^{\prime \prime}\right) \wedge \mathbf{a g}\left(e^{\prime \prime}\right)=\mathbf{j o h n}\right]\right]
\end{aligned}
$$

This translation is very weak. It amounts to saying "There is a time during which John did not laugh", without placing any constraints on when this time should be. So Krifka introduces further modifications inspired by the anaphoric treatment of tense in the style of Partee (1973). The net effect of these modifications is that the existentially quantified time variable $t$ is restricted to be a part of the reference time introduced by the past morpheme.

Krifka's fusion-based negation system has been both influential and controversially debated in the literature. For example, it plays an important role in the account of scopal effects of for-adverbials in Zucchi and White (2001) and in the formal reconstruction of various analyses of the meaning of until in de Swart (1996) and Condoravdi (2008). One of the main questions in these discussions regards the ontological status of fusions. Some authors (de Swart 1996; de Swart and Molendijk 1999) embrace these fusions and even take them as support for the claim that "negation is a stativizer", that is, negation yields predicates of states. However, this claim is controversial (Condoravdi 2008; Csirmaz 2006; Giannakidou 2002). In the absence of a consensus on the status of negation-based fusions, it is worth revisiting the evidence that led to their introduction in the first place.

In quantificational event semantics, we do not need to resort to mereological fusion for the treatment of negation, because one of the premises of the argument that leads to Krifka's scope dilemma is missing from our system. Since our event quantifier 
takes scope at the lowest possible level, the scopal interaction between for-adverbials and negation does not force us to conclude that negation takes scope under the event quantifier. This is so even if we also maintain, as Krifka does, that the for-adverbial never takes scope at the sentential level. As a result, we can formulate the meaning of not in terms of logical negation, without event fusions.

$$
\llbracket \operatorname{not} \rrbracket=\lambda V \lambda f . \neg V(f)
$$

I treat $\mathrm{did}$ as semantically vacuous. Its presence only morphologically signals the presence of past tense. This idea is common in semantic treatments of tense; see for example von Stechow (2009, Sect. 6), for details and references.

Sentence (27) receives the LF in (29a), which results in a straightforward translation that does not involve reference to fusions (29b):

$$
\begin{aligned}
& \text { a. [CP [closure] [[ }{ }_{\mathrm{DP}} \text { john [ag]] [ [v did not laugh ]]] } \\
& \text { b. } \neg \exists e[\operatorname{laugh}(e) \wedge \mathbf{a g}(e)=\mathbf{j o h n}]
\end{aligned}
$$

This translation ignores tense. Let us now add an anaphoric treatment of tense to restrict the translation to the reference time (written $t_{\mathbf{r}}$ ), again following Partee (1973). Since Krifka assumes such a treatment too, this move does not change the relative complexities of the two systems under comparison. Here and below, I write temporal inclusion as $\subseteq_{T}$ and temporal precedence as $\ll$. The following closure operator represents the meaning of the past tense:

$$
\begin{aligned}
& \mathbb{[}[\text { past-closure }] \rrbracket \\
& =\lambda V\left[t_{\mathbf{r}} \ll \mathbf{n o w} \wedge V\left(\lambda e\left[\tau(e) \subseteq \subseteq_{T} t_{\mathbf{r}}\right]\right)\right]
\end{aligned}
$$

In this entry, the subformula $t_{\mathbf{r}} \ll$ now is not in the scope of $V$. This, together with the fact that nothing ever takes scope above the closure operator, ensures that it is always interpreted with wide scope.

On the assumption that negation and for-adverbials can combine with the verb phrase in any order, the following translation of a for-adverbial generates the desired readings for (23).

$$
\begin{aligned}
& \text { 【for two hours》 } \\
& =\lambda V \lambda f \exists t\left[\operatorname{hours}(t)=2 \wedge t \subseteq t_{\mathbf{r}}\right. \\
& \left.\wedge \forall t^{\prime}\left[t^{\prime} \subseteq t \rightarrow V\left(\lambda e\left[f(e) \wedge \tau(e)=t^{\prime}\right]\right)\right]\right]
\end{aligned}
$$

My analyses of (23a) and (23b) are shown in (32) and (33) respectively. The full derivations are shown in Figs. 5 and 6 . In both LFs, the for-adverbial takes scope at VP level. Thus, we avoid resorting to the assumption that Krifka viewed as problematic, namely that the for-adverbial is able to take scope at sentential level. The occurrence of $t_{\mathbf{r}}$ in (31) is crucial; it prevents (32) from being trivially verified by any two-hour interval outside of the reference time.

(32) a. For two hours, it was not the case that John laughed.

b. [CP [[DP john [ag]] [ [vP [vP did not laugh ] [

c. $t_{\mathbf{r}} \ll$ now $\wedge \exists t\left[\operatorname{hours}(t)=2 \wedge t \subseteq_{T} t_{\mathbf{r}} \wedge \forall t^{\prime}\left[t^{\prime} \subseteq_{T} t \rightarrow\right.\right.$ $\left.\left.\neg \exists e\left[\operatorname{laugh}(e) \wedge \mathbf{a g}(e)=\mathbf{j o h n} \wedge \tau(e)=t^{\prime} \wedge t^{\prime} \subseteq_{T} t_{\mathbf{r}}\right]\right]\right]$ 


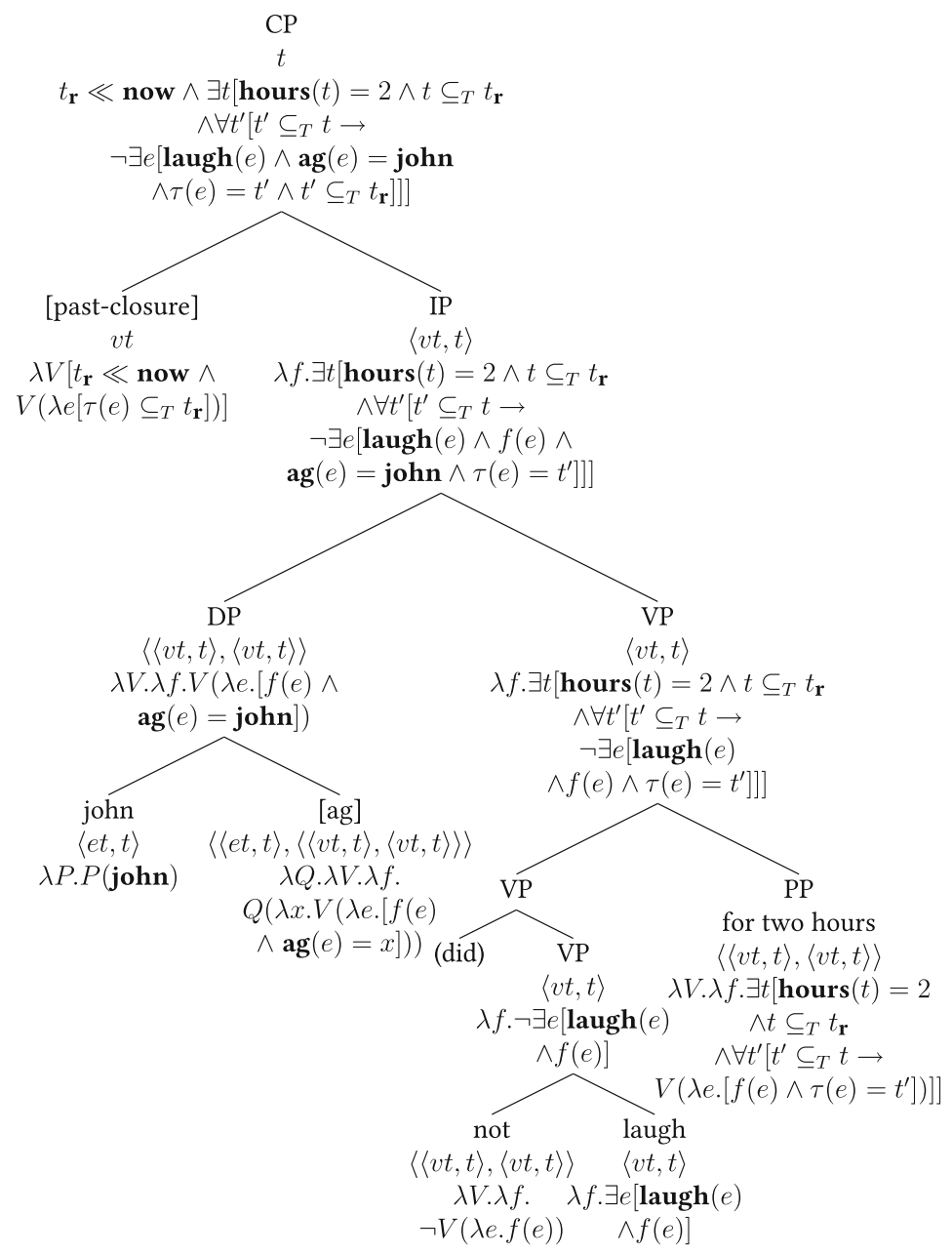

Fig. 5 LF for Example (32): John [didn't laugh] for two hours

(33) a. It was not the case that John laughed for two hours.

b. [CP [[op john [ag]] [vp did not [vp laugh [pp for 2 hours]]]]]

c. $t_{\mathbf{r}} \ll$ now $\wedge \neg \exists t\left[\right.$ hours $(t)=2 \wedge t \subseteq_{T} t_{\mathbf{r}} \wedge \forall t^{\prime}\left[t^{\prime} \subseteq_{T} t \rightarrow\right.$ $\left.\left.\exists e\left[\operatorname{laugh}(e) \wedge \mathbf{a g}(e)=\mathbf{j o h n} \wedge \tau(e)=t^{\prime} \wedge t^{\prime} \subseteq_{T} t_{\mathbf{r}}\right]\right]\right]$

In (31), I have followed Dowty (1979) and others in treating the for-adverbial as quantifying over subintervals of a two-hour-long interval, rather than quantifying over subevents of an event whose runtime is two hours, as in Krifka (1998) for example. Otherwise, in (23a) we would need to resort to something like a fusion-based treatment of negation after all, because in order for there to be a suitable two-hour event we would 


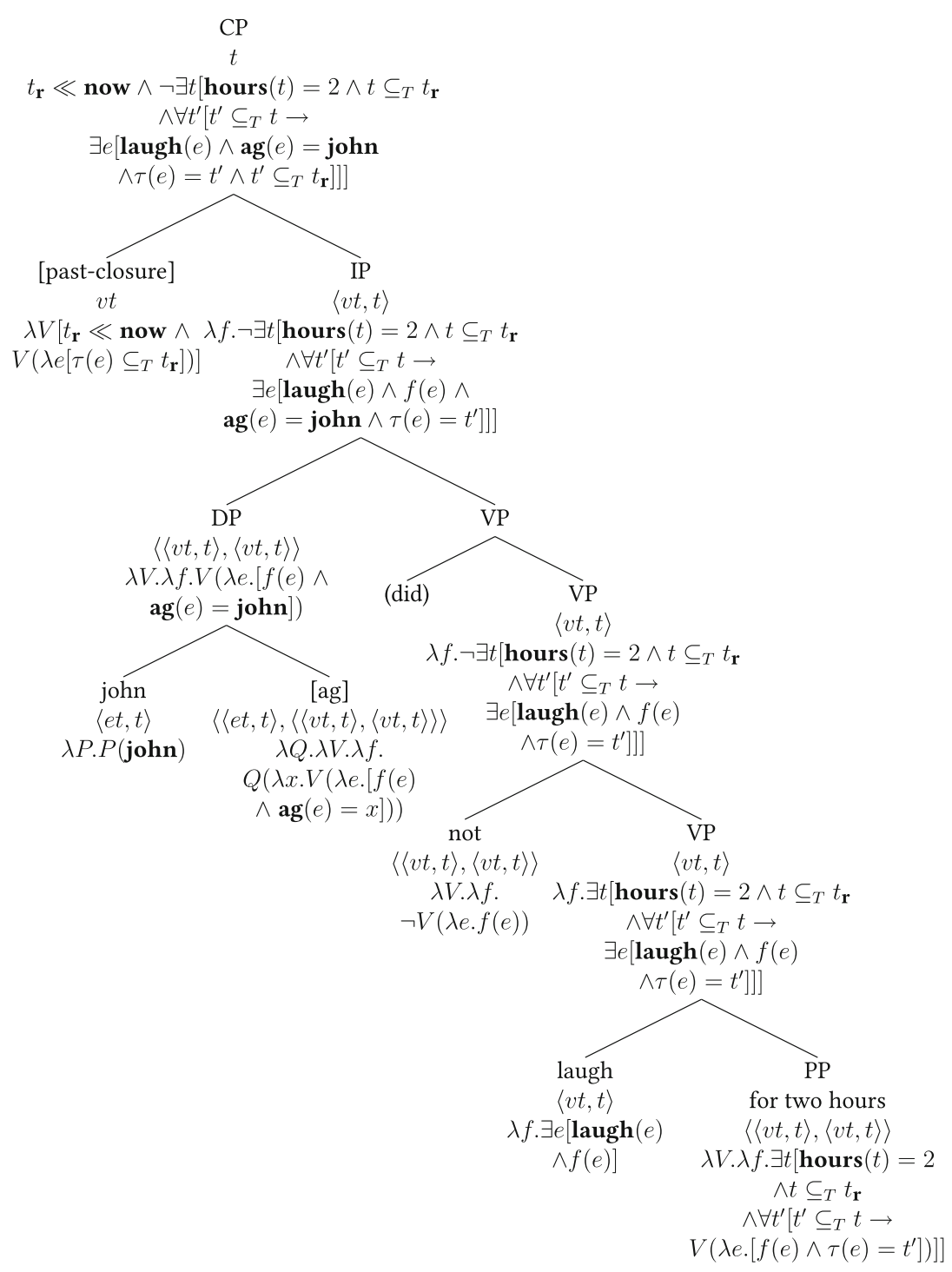

Fig. 6 LF for Example (33): John didn't [laugh for two hours]

need to introduce a "negative event" whose runtime would be the two hours in which John didn't laugh. For independent justification of the subinterval-based translation of the for-adverbial used here, and for an alternative account of its scopal behavior, see Champollion (2010b, Chaps.6and9).

A question I will not answer here is how to deal with negative perception and causation reports like the following, taken from Higginbotham (1983) and Higginbotham (1999) respectively: 
a. I saw Mary not leave.

b. I kept the child awake by not turning out the light.

These reports cannot be analyzed in terms of logical negation alone. Neither of the two following formulas captures the truth conditions of (34a) correctly (Higginbotham 1983).

$$
\begin{aligned}
& \text { a. } \exists e . \neg[\operatorname{leave}(e) \wedge \mathbf{a g}(e)=\operatorname{mary} \wedge e \in \llbracket[\text { saw } \rrbracket] \\
& \text { b. } \neg[\exists e . \operatorname{leave}(e) \wedge \mathbf{a g}(e)=\mathbf{m a r y} \wedge e \in[\text { I saw }]]
\end{aligned}
$$

Formula (35a) is trivially verified by almost any event, and formula (35b) is true even if Mary left, as long as the speaker didn't see her leave. The actual truth conditions of (34a) can be paraphrased as I saw Mary stay. But not every such report can be paraphrased so easily.

Such sentences have occasionally been analyzed in terms of negative events (Higginbotham 1999). As a reviewer notes, negative events bear some resemblance to the maximal fusions in Krifka's negation. This resemblance is only superficial, since the events arguably involved in these negative reports are not maximal in any clear sense. For example, applying Krifka's entry for negation to not turn the light off in (34b) gives us the property that holds of any maximal fusion of all the events that take place within some time during which the light was not turned off. Some of the events in such a fusion will have no causal relevance to the child being kept awake and should presumably not be part of any negative event that is provided by the complement clause of (34b). So negative perception and causation reports do not provide direct evidence for Krifka's maximal fusion events.

To conclude this section, let me briefly note that modals and other fixed-scope operators can be treated in the same way as I have treated negation. Setting aside the well-known intricacies of possible-world semantics, the lexical entry for modals like may and must will look like this:

$$
\begin{aligned}
& \llbracket \text { may }=\lambda V \lambda f \diamond V(\lambda e[f(e)]) \\
& \llbracket \text { must }=\lambda V \lambda f \square V(\lambda e[f(e)])
\end{aligned}
$$

For these entries to lead to interpretable formulas, the interpretation of the representation language must of course be suitably intensionalized. The details do not interact with quantificational event semantics.

To summarize this section, I have shown that truth-functional linguistic negation in event semantics can be given a classical interpretation in terms of logical negation $(\neg)$. To avoid misunderstandings, the point here is not to argue that mereology and fusions should be dispensed with. Event fusions by themselves are useful tools in many areas of formal semantics. I have alluded to them in Sect. 2 in connection with event anaphora (John kissed every girl. It took very long.) and I have used them elsewhere in mereology-based work (Champollion 2010b, 2014a,b). Rather, the point here was simply to establish that giving an account of negation in event semantics does not by itself require event fusions or a departure from logical negation. 


\section{Conjunction}

This section discusses the interaction of the present system with conjunctive coordination of verbs and verb phrases, focusing on the word and. This can be used both intersectively, as in John lies and cheats, and collectively, as in John and Mary met. This suggests that and is ambiguous between an intersective and a collective interpretation. Winter (2001) argues convincingly against the ambiguity assumption. This suggests one of two theories: on the collective or "non-boolean" theory, all occurrences of and are collective; on the intersective or "boolean" theory, all occurrences are intersective. The collective theory is pursued, in various guises and to various degrees, in Lasersohn (1995) and Heycock and Zamparelli (2005). For discussion and criticism of the collective theory and arguments for the intersective theory, see Champollion (2013, 2014d). In this section I show that the present framework easily supports the intersective theory. I compare and contrast the present framework with Lasersohn (1995, Chap.14). There are other implementations of coordination in event semantics besides Lasersohn's and the present one. For a type-logical implementation, see for example Forbes (2012). Here I focus on Lasersohn's argument that the interaction of event semantics with the meaning of the adverb alternately provides an argument for the collective theory. I refute this argument below. The upshot of this section will be that an intersective theory of coordination is at least equally viable in an event semantic framework. Thus, adopting event semantics does not commit us to choosing one theory of coordination over another.

Lasersohn makes the typical assumption (the one I have rejected in Sect. 2) that sentence radicals like John sang are interpreted as event predicates. He models sentencelevel and as a collective formation operator that acts on such sentence radicals, on a par with group-forming noun phrase conjunction. For example, "the sentence John sang and Mary danced can be interpreted as a predicate which truthfully applies to a group of events, one member of which is an event of John singing, and another member of which is an event of Mary dancing" (Lasersohn 1995, p. 268).

Lasersohn models collective events as sets. This is mainly motivated by his treatment of alternately, which I discuss at the end of this section (see also Winter (1995) for some critical remarks). He generalizes his entry for non-boolean and from the propositional case to arbitrary conjoinable types. (A conjoinable type is a type that "ends in t", that is, it is either $t$ or a type of the shape $\alpha \beta$ where $\alpha$ is any type whatsoever and $\beta$ is a conjoinable type.) In the special case of one-place predicates, this gives the following result:

$$
\begin{aligned}
& \text { a. } \llbracket \text { and } \rrbracket_{\text {Lasersohn }}=\lambda P_{1} \cdot \lambda P_{2} \cdot \lambda e . \exists e_{1} \exists e_{2} . P_{1}\left(e_{1}\right) \wedge P_{2}\left(e_{2}\right) \wedge e=\left\{e_{1}, e_{2}\right\} \\
& \text { b. } \llbracket \text { sing and dance } \rrbracket_{\text {Lasersohn }}=\lambda e . \exists e_{1} \exists e_{2} \cdot \operatorname{sing}\left(e_{1}\right) \wedge \text { dance }\left(e_{2}\right) \wedge e=\left\{e_{1}, e_{2}\right\}
\end{aligned}
$$

Generalized intersective and amounts to intersection both in the case of predicate conjunction and in the case of quantifier conjunction. This can be seen from the application of the following recursive rule (e.g. Partee and Rooth 1983). Let $\tau$ range over conjoinable types, and let $\sigma_{1}$ and $\sigma_{2}$ range over any type. Then define generalized intersection as follows and identify the meaning of and with it: 


$$
\Pi_{\langle\tau, \tau \tau\rangle}=\operatorname{def} \begin{cases}\wedge\langle t, t t\rangle & \text { if } \tau=t \\ \lambda X_{\tau} \lambda Y_{\tau} \lambda Z_{\sigma_{1}} . X(Z) \Pi_{\left\langle\sigma_{2}, \sigma_{2} \sigma_{2}\right\rangle} Y(Z) & \text { if } \tau=\left\langle\sigma_{1}, \sigma_{2}\right\rangle\end{cases}
$$

Roughly, this says that a conjunction of sentences $S_{1}$ and $S_{2}$ is true whenever both of the conjuncts are true, and a conjunction of subsentential constituents $C_{1}$ and $C_{2}$ denotes their intersection. The application of this rule to event predicates and event quantifiers is as follows:

(40) Conjunction of event predicates:

$\left[\lambda e . F_{v t}(e)\right] \sqcap_{\langle v t,\langle v t, v t\rangle\rangle}\left[\lambda e . G_{v t}(e)\right]$

$=\left[\lambda e \cdot F_{v t}(e) \wedge G_{v t}(e)\right]$

\section{Conjunction of event quantifiers (this system):}

$$
\begin{aligned}
& {\left[\lambda f . \exists e \cdot F_{v t}(e) \wedge f(e)\right] \sqcap\langle\langle v t, t\rangle,\langle\langle v t, t\rangle,\langle v t, t\rangle\rangle\rangle\left[\lambda f . \exists e . G_{v t}(e) \wedge f(e)\right]} \\
& =\left[\lambda f .\left[\exists e . F_{v t}(e) \wedge f(e)\right] \wedge\left[\exists e^{\prime} . G_{v t}\left(e^{\prime}\right) \wedge f\left(e^{\prime}\right)\right]\right]
\end{aligned}
$$

The important thing to notice about these two applications is that in (40), there is no event quantifier, while in (41), there are two. So the assumption that verbal projections are interpreted as event predicates, as in (40), is not readily compatible with the intersective theory of and because it forces both verbal predicates to apply to the same event. Take Davidson's example of a ball that is at once rotating quickly and heating up slowly (Davidson 1969). This example is generally taken to show that there must be two events involved, since one and the same event cannot be both quick and slow. If the conjoined verb phrases in sentence (42) are interpreted as event predicates, as in (43a), they cannot be interpreted intersectively. (I assume that intersective adverbs have entries as in (44).) By contrast, if the conjoined verb phrases are interpreted as event quantifiers, as in quantificational event semantics, the intersective interpretation is unproblematic. This is because rule (39) ends up causing logical conjunction to have wide scope over the event quantifiers (43b).

(42) The ball rotated quickly and heated up slowly.

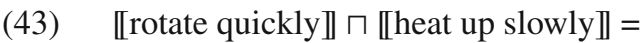

$$
\begin{array}{ll}
\text { a. } & \lambda e \cdot \operatorname{rotate}(e) \wedge \text { quickly }(e) \wedge \text { heat-up }(e) \wedge \operatorname{slowly}(e) \\
\text { b. } & \lambda f .[\exists e . \operatorname{rotate}(e) \wedge \text { quickly }(e) \wedge f(e)] \\
& \wedge\left[\exists e^{\prime} \cdot \operatorname{heat}-\mathbf{u p}\left(e^{\prime}\right) \wedge \operatorname{slowly}\left(e^{\prime}\right) \wedge f\left(e^{\prime}\right)\right]
\end{array}
$$

$$
\llbracket \text { quickly }=\lambda V . \lambda f . V(\lambda e . q u i c k l y(e) \wedge f(e))
$$

When the verb phrase denotation (43b) is combined with the denotation of the subject in the same way as is illustrated in Fig. 2, the result predicts that sentence (42) is true just in case there is an event $e$ in which the ball rotated quickly and there is an event $e^{\prime}$ in which it heated up slowly. If desired, one can furthermore apply the treatment of tense presented in Sect. 3 in order to narrow down the reference time interval in which sentence (42) situates the two events. When the length of that interval is zero, the two events are required to be simultaneous.

The treatment of verbs as involving event quantifiers also provides us with a way to treat the scopal interaction of conjunction and indefinites. Sentence (45) is usually 
discussed with respect to the relative scope of the conjunction and the indefinite (Rooth and Partee 1982; Partee and Rooth 1983).

John caught and ate a fish.

Rooth and Partee (1982) claim that this sentence only has a "one fish" reading (where the indefinite takes scope over the conjunction, i.e. John ate the fish he caught), and lacks a "two fish" reading (i.e. John caught a fish and ate a fish). They note that the "one fish" reading is generated by the entry in (39) if transitive verbs are assumed to have type $\langle e, e t\rangle$, rather than $\langle\langle e t, t\rangle, e t\rangle$ as in Montague (1973). Hendriks (1993) disagrees with their judgment and argues that the "two fish" reading is dispreferred for pragmatic reasons (because it can also be expressed in a less ambiguous way as John caught a fish and ate a fish) but that it is available with the right continuation:

(46) John caught and ate a fish. The fish he caught was inedible, and the fish he ate caught his eye.

Judgments on this kind of sentence vary. Bittner (1994) claims that (47a) "intuitively requires that there be some car that John bought and sold", while Winter (1995) claims, following Hendriks (1993, p. 52) that the "prominent reading" of the similar sentence (47b) is the one that can be paraphrased as "John sold a car and bought a car". A reviewer provides (47c) and (47d) as two more examples that favor the two-fish reading.
a. John bought and sold a car.
b. John sold and bought a car.
c. John caught and drew a fish.
d. John ate and caught a fish.

Once we move into event semantics, a new issue besides the scope of the indefinite arises: what are the thematic roles assigned by the various verbs involved? In (45), does the catching event stand in the same relation (say, theme) vis-à-vis the fish that was caught as the eating event does vis-à-vis the fish that was eaten, or are there two different relations (I'll call them prey and food)? And does John stand in the same relation (say agent) to both events, or is he the catcher of one event and the eater of the other?

To some extent, this question is resolved as a theory-internal matter. For general discussion, see Dowty (1991). On the traditional view of thematic roles, represented e.g. in Gruber (1965) and Jackendoff (1972), thematic roles encapsulate generalizations over shared entailments of argument positions in different predicates. Thus, in the fish scenario it is possible for John to stand in the same relation (agent) to both the catching event and the eating event, since in each case there is a sense in which John initiates the event, is responsible for it, etc. An alternative, more fine-grained, view sees thematic roles as verb-specific relations (Marantz 1984): John stands in two different relations (catcher and eater) to the two events, and the same holds for the fish (prey and food). The difference between incremental and holistic themes, which is relevant to theories of aspectual composition, may perhaps be taken as an intermediate position between the two (Dowty 1991; Krifka 1998). Coordination of verbal 
predicates may (and on the verb-specific view, must) involve different thematic roles. Unergative verbs, whose subjects are agents, can be coordinated with unaccusative verbs, whose subjects are non-agents. A simple example is the following:

John laughed and fell.

Here, I illustrate that the present framework can accommodate coordination of various kinds. Let us start with the simplest case: assume that there are only two thematic roles at play, agent and theme. I will withdraw this assumption below. On this view, the "one-fish" reading of (45) is represented as follows.

$$
\begin{aligned}
& {\left[\exists x \cdot \operatorname { f i s h } ( x ) \wedge [ \exists e \cdot \operatorname { c a t c h } ( e ) \wedge \operatorname { a g } ( e ) = j \wedge \operatorname { t h } ( e ) = x ] \wedge \left[\exists e^{\prime} \cdot \operatorname{eat}\left(e^{\prime}\right) \wedge \operatorname{ag}\left(e^{\prime}\right)=\right.\right.} \\
& \left.\left.j \wedge \operatorname{th}\left(e^{\prime}\right)=x\right]\right]
\end{aligned}
$$

Here is how the verb phrase of this reading is derived.

$$
\begin{aligned}
& \text { a. } \mathbb{\| [} \text { catch and eat }] \rrbracket=\lambda f .[\exists e \cdot \operatorname{catch}(e) \wedge f(e)] \wedge\left[\exists e^{\prime} \text {.eat }\left(e^{\prime}\right) \wedge f\left(e^{\prime}\right)\right] \\
& \text { b. } \mathbb{[}[\mathrm{th}] \rrbracket=\lambda Q \lambda V \lambda f[Q(\lambda x[V(\lambda e[f(e) \wedge \operatorname{th}(e)=x])])] \quad=(18) \\
& \text { c. } \mathbb{\|}[\mathrm{a} \text { fish }] \rrbracket=\lambda P \exists x \text {.fish }(x) \wedge P(x)
\end{aligned}
$$

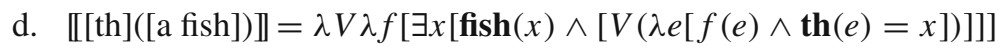

$$
\begin{aligned}
& \text { e. } \mathbb{[ L}[\mathrm{th}]([\mathrm{a} \text { fish }]) \rrbracket([[\text { catch and eat }] \rrbracket)=\lambda f[\exists x \cdot \mathbf{f i s h}(x) \wedge[\exists e \cdot \operatorname{catch}(e) \wedge \\
& \left.f(e) \wedge \operatorname{th}(e)=x] \wedge\left[\exists e^{\prime} \cdot \operatorname{eat}\left(e^{\prime}\right) \wedge f\left(e^{\prime}\right) \wedge \operatorname{th}\left(e^{\prime}\right)=x\right]\right]
\end{aligned}
$$

This derivation involves conjoining the verbs directly, and applying the thematic role head to the object before the result is applied to the conjunction.

As for the "two-fish" reading, for those speakers that have it, we can generate it by adding an additional lexical entry for our silent theme head into the grammar - call it [th2]. This entry combines first with the verb and then with the object, rather than the other way around as [th] does. To generate the "two-fish" reading, we first attach [th2] to each of the verbs, then use the entry in (39) to intersect the meanings of the resulting constituents, and finally apply the conjunction to the object quantifier. Here, we exploit the fact that our theme heads expect their arguments to be of type $\langle e t, t\rangle$, similarly to the transitive verbs in Montague (1973). The full derivation of the verb phrase is as follows:

$$
\begin{aligned}
& \text { a. } \quad[[\operatorname{th} 2] \rrbracket=\lambda V \lambda Q \lambda f[Q(\lambda x[V(\lambda e[f(e) \wedge \operatorname{th}(e)=x])])] \\
& \text { b. } \llbracket \text { catch } \rrbracket=\lambda f . \exists e \cdot \operatorname{catch}(e) \wedge f(e) \\
& \text { c. } \llbracket[[\operatorname{th} 2] \text { catch }] \rrbracket=\lambda Q \lambda f[Q(\lambda x[\exists e \cdot \operatorname{catch}(e) \wedge[f(e) \wedge \operatorname{th}(e)=x]])] \\
& \text { d. }\left[[[\text { th2 }] \text { eat }] \rrbracket=\lambda Q \lambda f\left[Q\left(\lambda y\left[\exists e^{\prime} \cdot \operatorname{eat}\left(e^{\prime}\right) \wedge\left[f\left(e^{\prime}\right) \wedge \operatorname{th}\left(e^{\prime}\right)=y\right]\right]\right)\right]\right. \\
& \text { e. } \mathbb{[}[[\text { th2 }] \text { catch }] \text { and [[th2] eat }]]]=\lambda Q \lambda f[Q(\lambda x[\exists e \cdot \operatorname{catch}(e) \wedge[f(e) \wedge \\
& \operatorname{th}(e)=x]])] \sqcap \lambda Q \lambda f\left[Q\left(\lambda y\left[\exists e^{\prime} . \operatorname{eat}\left(e^{\prime}\right) \wedge\left[f\left(e^{\prime}\right) \wedge \operatorname{th}\left(e^{\prime}\right)=y\right]\right]\right)\right] \\
& =\lambda Q \cdot \lambda f \cdot[Q(\lambda x[\exists e \cdot \operatorname{catch}(e) \wedge[f(e) \wedge \operatorname{th}(e)=x]]) \\
& \left.\wedge Q\left(\lambda y\left[\exists e^{\prime} . \operatorname{eat}\left(e^{\prime}\right) \wedge\left[f\left(e^{\prime}\right) \wedge \operatorname{th}\left(e^{\prime}\right)=y\right]\right]\right)\right] \\
& \text { f. } \quad \llbracket[\text { a fish }] \rrbracket=\lambda P \exists x \text {.fish }(x) \wedge P(x) \\
& \text { g. } \llbracket(51 \mathrm{e}) \rrbracket(\llbracket(51 \mathrm{f}) \rrbracket)=\lambda f \text {. } \\
& {[\exists x \cdot \operatorname{fish}(x) \wedge \exists e \cdot \operatorname{catch}(e) \wedge f(e) \wedge \operatorname{th}(e)=x]} \\
& \wedge\left[\exists y \cdot \operatorname{fish}(y) \wedge \exists e^{\prime} . \operatorname{eat}\left(e^{\prime}\right) \wedge f\left(e^{\prime}\right) \wedge \operatorname{th}\left(e^{\prime}\right)=y\right]
\end{aligned}
$$


Since we have made use of the [th2] lexical entry here but we have left the entry of the verb unchanged, we can make [th2] available on a per-speaker basis. For example, the grammars of M. Rooth, B. Partee, and M. Bittner (or of the speakers they consulted) have only one lexical entry for the theme head, namely [th], while the grammars of $\mathrm{H}$. Hendriks and Y. Winter have two, namely [th] and [th2].

Let us now withdraw the assumption that the same thematic role is involved in the catching and in the eating. The derivation of the "two-fish" reading involves the application of two thematic heads [th2], as shown in (51e). We could easily replace each of them by a different verb-specific theta role head whose meaning is identical to [th2] except for the relation involved. The "one-fish" reading as it has been derived in (50) involves the application of only one thematic head and so it cannot be retrofitted to accommodate two different thematic roles. Instead, we need to provide a third type of entry, one that can combine with verbs as in (51) but that does not assume that its argument is quantificational. After the two verbs combine with their role heads, they are coordinated by intersective conjunction, and the result is prepared for the quantificational argument by an application of Value Raising, a generalization of the Montague-lift (Hendriks 1993).

This is illustrated in the following derivation, where [pre] stands for the thematic role head that denotes the thematic relation prey, which holds between a catching event and the entity caught in it, and [foo] stands for the head that denotes the thematic relation food, which holds between an eating event and the entity eaten in it. I write [vr] for my approximation of Value Raising. I only give the specific instantiation of Value Raising that is needed in this case, rather than the general rule.

$$
\begin{aligned}
& \text { a. } \quad \llbracket[\text { pre }] \rrbracket=\lambda V \lambda x \lambda f . V(\lambda e[f(e) \wedge \operatorname{prey}(e)=x]) \\
& \text { b. } \llbracket[\text { foo }] \rrbracket=\lambda V \lambda x \lambda f . V(\lambda e[f(e) \wedge \operatorname{food}(e)=x])
\end{aligned}
$$

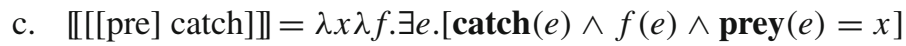

$$
\begin{aligned}
& \text { d. } \llbracket[[\text { foo }] \text { eat }] \rrbracket=\lambda x \lambda f . \exists e .[\operatorname{eat}(e) \wedge f(e) \wedge \operatorname{food}(e)=x]
\end{aligned}
$$

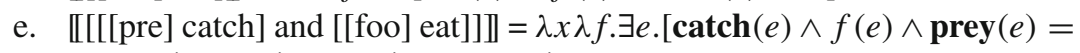

$$
\begin{aligned}
& x] \wedge \exists e^{\prime} \cdot\left[\operatorname{eat}\left(e^{\prime}\right) \wedge f\left(e^{\prime}\right) \wedge \operatorname{food}\left(e^{\prime}\right)=x\right] \\
& \text { f. } \quad \llbracket[\mathrm{vr}] \rrbracket=\lambda A_{\langle e,\langle v t, v t\rangle\rangle} \lambda Q_{\langle e, e t\rangle} \lambda f . \lambda e \cdot Q(\lambda x . A(x)(f)(e)) \\
& \text { g. } \llbracket(52 \mathrm{f}) \rrbracket(\llbracket(52 \mathrm{e}) \rrbracket)=\lambda Q \cdot \lambda f . \exists e \cdot Q(\lambda x \cdot[\operatorname{catch}(e) \wedge f(e) \wedge \operatorname{prey}(e)=x] \wedge \\
& \left.\exists e^{\prime} \cdot\left[\operatorname{eat}\left(e^{\prime}\right) \wedge f\left(e^{\prime}\right) \wedge \operatorname{food}\left(e^{\prime}\right)=x\right]\right) \\
& \text { h. } \llbracket[\text { a fish }] \rrbracket=\lambda P \exists x \text {.fish }(x) \wedge P(x) \\
& \text { i. } \quad \llbracket(52 \mathrm{~g}) \rrbracket(\llbracket(52 \mathrm{~h}) \rrbracket)=\lambda f . \exists e . \exists x \cdot \operatorname{fish}(x) \wedge[\operatorname{catch}(e) \wedge f(e) \wedge \operatorname{prey}(e)= \\
& x] \wedge \exists e^{\prime} \cdot\left[\operatorname{eat}\left(e^{\prime}\right) \wedge f\left(e^{\prime}\right) \wedge \operatorname{food}\left(e^{\prime}\right)=x\right]
\end{aligned}
$$

What this derivation shows is that the assumption that thematic roles are verb-specific (and the weaker assumption that the same argument can stand in two different thematic relations to two conjoined verbs) can be accommodated, although this requires us to assume thematic role heads of a new semantic type, and it requires Value Raising or a similar adjustment.

One noteworthy feature of the derivation in (52) is that it keeps track of the two different thematic roles in the right way. That is, the resulting denotation for caught and ate a fish combines the catching event with the prey relation, and the eating event with the food relation. In this way, the semantics mirrors and preserves the 
syntactic relationship between the verb catch and the thematic role head [pre], and the one between the verb eat and the thematic role head [foo]. Each of these syntactic relationships is local and can be enforced by whatever syntactic mechanism takes care of subcategorization. That the semantics keeps track of these relationships is an improvement over the system in Lasersohn (1995). That system does not specify a mechanism to keep track, and is criticized for this reason by Winter (2001, p.43). Sentence (53) is discussed by Winter as being problematic for Lasersohn's account. I provide a derivation below. It is parallel to (52) above, except that we do not need to apply value raising since the subject is not a quantifier. For consistency with Lasersohn and Winter, I represent the thematic role heads involved as $\Theta_{\text {sing }}$ and $\Theta_{\text {dance }}$.

John sang and danced.
a. $\llbracket \Theta_{\text {sing }} \rrbracket=\lambda V \lambda x \lambda f . V(\lambda e[f(e) \wedge \operatorname{singer}(e)=x])$
b. $\llbracket \Theta_{\text {dance }} \rrbracket=\lambda V \lambda x \lambda f . V(\lambda e[f(e) \wedge \operatorname{dancer}(e)=x])$
c. $\mathbb{[}\left[\left[\Theta_{\text {sing }}\right] \operatorname{sing}\right] \rrbracket=\lambda x \lambda f . \exists e .[\operatorname{sing}(e) \wedge f(e) \wedge \operatorname{singer}(e)=x]$
d. $\llbracket\left[\left[\Theta_{\text {dance }}\right]\right.$ dance $] \rrbracket=\lambda x \lambda f . \exists e .[\operatorname{dance}(e) \wedge f(e) \wedge \operatorname{dancer}(e)=x]$
e. $\mathbb{[}\left[\left[\left[\Theta_{\text {sing }}\right]\right.\right.$ sing $]$ and $\left[\left[\Theta_{\text {dance }}\right]\right.$ dance $\left.]\right] \rrbracket=\lambda x \lambda f . \exists e \cdot[\operatorname{sing}(e) \wedge f(e) \wedge$ $\operatorname{singer}(e)=x] \wedge \exists e^{\prime} .\left[\operatorname{dance}\left(e^{\prime}\right) \wedge f\left(e^{\prime}\right) \wedge \operatorname{dancer}\left(e^{\prime}\right)=x\right]$
f. $\llbracket \mathrm{John} \rrbracket=j$
g. $\llbracket(53 \mathrm{e}) \rrbracket(\llbracket(53 \mathrm{f}) \rrbracket)=$

$$
\begin{aligned}
& \lambda f . \exists e .[\operatorname{sing}(e) \wedge f(e) \wedge \operatorname{singer}(e)=j] \wedge \\
& \exists e^{\prime} .\left[\operatorname{dance}\left(e^{\prime}\right) \wedge f\left(e^{\prime}\right) \wedge \operatorname{dancer}\left(e^{\prime}\right)=j\right]
\end{aligned}
$$

This last step, $(53 \mathrm{~g})$, is the meaning of the sentence radical, and it holds of any set of events just in case it contains a singing event whose singer is John, and a dancing event whose dancer is John. As before, we can then either immediately apply closure, or if we want to model the contribution of tense, we can apply a semantic tense morpheme in order to require the two events to be contained in the reference time.

Let me now discuss Lasersohn's treatment of alternately, since he takes it as motivation for the collective theory of coordination, and specifically for the view that sing and dance denotes a predicate which is true of collective events that consist of a singing and a dancing. I will show how Lasersohn's treatment can in fact be implemented in the present system even though I have adopted the intersective theory of coordination rather than the collective theory. Lasersohn takes alternately to denote a modifier of event predicates, as shown in the following entry (Lasersohn 1995, p. 274). Here $P$ is a predicate of events, $X$ is a collective event, $\tau$ is the runtime function, and $\circ$ denotes overlap. Collective events are modeled as sets. (Lasersohn adds the condition $e \notin P$ for theory-internal reasons that are irrelevant for the present purpose.)

$$
X \in \llbracket \text { alternately } \rrbracket(P) \text { iff } X \in P \wedge \forall e, e^{\prime} \in X\left[e \notin P \wedge \neg\left[\tau(e) \circ \tau\left(e^{\prime}\right)\right]\right]
$$

Lasersohn assumes that a conjoined event predicate $P$ like sing and dance denotes the set of all collective events $\left\{e, e^{\prime}\right\}$ that contain a singing event $e$, a dancing event $e^{\prime}$, and nothing else. The effect of applying the entry in (54) to sing and dance consists in eliminating those pairs whose members have overlapping runtimes, and in particular those pairs whose members are simultaneous. The result is that a conjoined verb phrase of the shape alternately $P$ and $Q$, where $\mathrm{P}$ and $\mathrm{Q}$ are action predicates, will hold of a 
subject $x$ just in case $x$ did one instance of a P action and one non-overlapping instance of a $\mathrm{Q}$ action. As Lasersohn notes, this can easily be modified if one feels that more than one instance of each type of action is necessary for alternation. I will come back to this point at the end of this section.

I now show how we can import Lasersohn's account into the present account by making use of set minimization, which allows us to simulate the effects of collective conjunction in an intersective framework (Winter 2001; Champollion 2014d). Set minimization is defined formally as follows, where $\tau$ is any conjoinable type:

$$
\min ={ }_{\text {def }} \lambda V_{\tau t} \lambda A_{\tau} . A \in V \wedge \forall B \in V[B \subseteq A \rightarrow B=A]
$$

Minimization takes a set of sets $V$ and returns the set of all those sets that are contained in $V$ but that do not have any proper subsets that are contained in $V$. For example, when we intersect the generalized quantifiers that we obtain by value-raising the constants John and Mary and minimize the result, we get the set $\{\{j, m\}\}$.

Now let us apply set minimization to recover Lasersohn's collective events from our verb phrases. Take for example the conjoined verb phrase sing and dance, whose denotation is shown in (53e). For purposes of exposition, let us ignore for a moment the fact that the subject is abstracted over, and assume that it is already fixed to the individual John. Then the simplified denotation of sing and dance is as follows:

$$
\begin{aligned}
& \llbracket \text { sing and dance } \|_{\text {simplified }} \\
& =\lambda f . \exists e .[\operatorname{sing}(e) \wedge f(e) \wedge \operatorname{singer}(e)=j] \wedge \exists e^{\prime} .\left[\text { dance }\left(e^{\prime}\right) \wedge f\left(e^{\prime}\right) \wedge\right. \\
& \text { dancer } \left.\left(e^{\prime}\right)=j\right]
\end{aligned}
$$

This is the set of all sets that contain a singing event by John and a dancing event by John. The result of applying set minimization to this is the set of all minimal sets that contain a singing event by John and a dancing event by John. Assuming that no event is both a singing and a dancing event, this means that set minimization will return the set of all two-element sets that contain a singing event by John and a dancing event by John. This is precisely the denotation that Lasersohn attributes to the verb phrase sing and dance, as shown in (38b), repeated here as (57):

$$
\begin{aligned}
& \llbracket \text { sing and dance } \rrbracket_{\text {Lasersohn }} \\
& =\lambda e \cdot \exists e_{1} \exists e_{2} \cdot \operatorname{sing}\left(e_{1}\right) \wedge \operatorname{dance}\left(e_{2}\right) \wedge e=\left\{e_{1}, e_{2}\right\}
\end{aligned}
$$

Putting the pieces together involves an additional step, since our denotation for sing and dance abstracts over the subject, as shown in (53e), repeated here as (58):

$$
\begin{aligned}
& \llbracket \text { sing and dance } \rrbracket=\lambda x \lambda f . \exists e .[\operatorname{sing}(e) \wedge f(e) \wedge \operatorname{singer}(e)=x] \wedge \\
& \exists e^{\prime} .\left[\text { dance }\left(e^{\prime}\right) \wedge f\left(e^{\prime}\right) \wedge \operatorname{dancer}\left(e^{\prime}\right)=x\right]
\end{aligned}
$$

This difference to Lasersohn's account is what allowed us earlier to avoid the problem diagnosed for it by Winter (2001). It is the fact that we abstract over the subject that helps us keep track of the pairing of thematic roles with verbs.

My entry for alternately, shown in (59), combines with a verb phrase $V$ of the type of the one in (58) and with a subject. The result can then be further modified by tense if desired, and closed off by the closure operator. 


$$
\begin{aligned}
& \text { 【alternately } \rrbracket=\lambda V_{\langle e,\langle v t, t\rangle\rangle} \lambda x \lambda f \exists e_{1} \exists e_{2} .\left[\neg \tau\left(e_{1}\right) \circ \tau\left(e_{2}\right)\right] \\
& \wedge\left\{e_{1}, e_{2}\right\} \in \min (V(x)) \wedge f\left(e_{1}\right) \wedge f\left(e_{2}\right)
\end{aligned}
$$

For example, if we ignore tense, the meaning of John alternately sang and danced comes out as follows:

$$
\begin{aligned}
& \llbracket J o h n \text { alternately sang and danced } \rrbracket=\exists e_{1} \exists e_{2} .\left[\neg \tau\left(e_{1}\right) \circ \tau\left(e_{2}\right)\right] \wedge \\
& \left\{e_{1}, e_{2}\right\} \in \min (\lambda f . \exists e .[\operatorname{sing}(e) \wedge \operatorname{singer}(e)=j] \wedge \\
& \left.\exists e^{\prime} .\left[\text { dance }\left(e^{\prime}\right) \wedge \operatorname{dancer}\left(e^{\prime}\right)=j\right]\right)
\end{aligned}
$$

Given the above discussion about minimization, this is equivalent to the following:

$$
\begin{aligned}
& \exists e_{1} \exists e_{2} . \neg \tau\left(e_{1}\right) \circ \tau\left(e_{2}\right) \wedge \\
& \operatorname{sing}\left(e_{1}\right) \wedge \operatorname{singer}\left(e_{1}\right)=j \wedge \operatorname{dance}\left(e_{2}\right) \wedge \operatorname{dancer}\left(e_{2}\right)=j
\end{aligned}
$$

This is true just in case John sang and danced but not at the same time, as desired. Thus, Lasersohn's account of alternately can be implemented independently of whether one takes the meaning of verb phrase conjunction to be intersective (as I do) or collective (as Lasersohn does).

A final remark on alternately. As mentioned above, Lasersohn notes that his entry can easily be modified if one feels that more than one instance of each type of action is necessary for alternation. For example, John alternately sang and danced probably requires him to go through more than just one alternation (that is, a change from singing to dancing or the other way round). We can also modify the entry in (59) in the same way. For example, suppose that three alternations are required. To make things simpler, assume that state changes require temporal adjacency. John sings until a certain point, at which he stops singing and starts dancing. This could be relaxed if desired, but I will not do so. Let us say that event $e_{1}$ abuts event $e_{2}$, written $e_{1} \supset e_{2}$, iff the runtime of $e_{1}$ ends at the same time as the runtime of $e_{2}$ starts. The following entry ensures that three alternations are required.

$$
\begin{aligned}
& \llbracket \text { alternately2 } \rrbracket=\lambda C_{\langle e,\langle v t, t\rangle\rangle} \lambda x \lambda f \exists e_{1} \ldots e_{4} \cdot\left[e_{1} \supset e_{2} \supset e_{3} \supset e_{4}\right] \wedge \\
& \left\{\left\{e_{1}, e_{2}\right\},\left\{e_{2}, e_{3}\right\},\left\{e_{3}, e_{4}\right\}\right\} \subseteq \min (C(x)) \wedge f\left(e_{1}\right) \wedge \ldots \wedge f\left(e_{4}\right)
\end{aligned}
$$

This entry has the consequence, for example, that John alternately sang and danced is true iff there are four pairwise abutting events $e_{1}$ to $e_{4}$ such that each abutting pair in them is a minimal element of the set of sets sing and dance, that is, the pair consists of a singing and a dancing. These pairs overlap and thereby enforce alternation. For example, if $e_{1}$ happens to be a singing, then $e_{2}$ must be a dancing, which in turn means that $e_{3}$ must be a singing again and so on. So we can capture the meaning of alternately correctly (as can Lasersohn) no matter how many alternations are felt to be required.

Summing up this section, the argument in Lasersohn (1995) that alternately favors the collective theory over the intersective theory does not go through. Assuming that Lasersohn's own theory can be amended to address the criticisms leveled against it by Winter (2001), adopting event semantics does not commit us to choosing one theory of coordination over another. In particular, adopting the intersective theory is compatible with event semantics. 


\section{Previous work: Beaver and Condoravdi (2007)}

This section provides a comparison of the present system with "linking semantics", the system presented by Beaver and Condoravdi (2007, here B\&C). This system is taken here as a representative example of previous work on the interaction of compositional semantics and event semantics. Its authors present it as surpassing both (Neo-)Montagovian semantics and Davidsonian event semantics. Like the present one, B\&C's system is designed to provide a clean and compositional account of the interaction of events and quantifiers. But the system adopts a nonstandard view of the semantics of action sentences that does not use events, and this leads to problems. The main point of this section is that we can have our cake and eat it too: we can reconcile B\&C with Davidsonian event semantics and keep the strengths of both systems. This section only provides a summary. For a more detailed argument, see Champollion (to appear-a).

The main idea in $\mathrm{B} \& \mathrm{C}$ is that verbs and verbal projections denote sets of "role assignments", that is, partial functions that map labels like ARG1, ARG2 and T (intuitively, agent, theme, and time) to appropriate values. So in a model where John kicked Bill at 1pm, the sets denoted by kick, by kick Bill and by John kick Bill each contain at least the role assignment $g_{1}=$ [ARG1, $j$; ARG2, $b$; T, 1 pm]. Among the strengths of B\&C's system are a clean and compositional account of the interaction of events and quantifiers, and an account of stacked temporal modification. The system in B\&C derives all the results described so far. In particular, their treatment of quantification, which they see as their main advantage over event semantics, is very similar to mine. However, their move away from event semantics is not free of drawbacks.

The first problem concerns argument reduction. In event semantics, verbal modifiers like at noon and in the bathroom are interpreted conjunctively, so that entailments like (63a) are modeled as logical entailments (63b) (Carlson 1984; Parsons 1990). This treatment of verbal modification is considered a very powerful argument in favor of event semantics (Landman 2000, Chap. 1). In B\&C's system, the corresponding entailment in (63c) is non-logical and needs to be stipulated for each verb $\mathrm{V}$ via an "argument reduction" principle that says that if $\mathrm{V}$ holds of a role assignment, $\mathrm{V}$ also holds of any restriction of the same assignment so long as its domain still contains all the arguments of V. (In other words, the principle always makes it possible to remove adjuncts but it does not apply to arguments proper, despite its name.) Thus, a major motivation for Davidsonian event semantics as a logic of verbal modification fails to carry over to B\&C's account. This is the case independently of whether the argumentadjunct distinction is treated purely syntactically, as I have done above, or whether it is mirrored in the semantics, as in B\&C's argument reduction principle.

(63) a. Jones buttered the toast at noon. $\Rightarrow$ Jones buttered the toast.

b. $[\exists e . \operatorname{butter}(e) \wedge \operatorname{ag}(e)=j \wedge \operatorname{th}(e)=$ toast $\wedge \tau(e)=$ noon] $\Rightarrow[\exists e \cdot \operatorname{butter}(e) \wedge \operatorname{ag}(e)=j \wedge$ th $(e)=$ toast $]$

c. butter([ARG1, $j$; ARG2, toast; toast, noon]) $\Rightarrow$ butter([ARG1, $j ;$ ARG2, toast $])$ 
The second problem concerns the treatment of time in $\mathrm{B} \& \mathrm{C}$. They represent the surface scope reading of a sentence like (64a) as in (64b). This would be too strong because it requires all the visits to happen simultaneously at time $t$. To avoid this, B\&C stipulate a "temporal closure" principle: if a verb applies to a role assignment which maps $\mathrm{T}$ to a given interval $t$, then for each of its superintervals $t^{\prime}$, the verb also applies to an otherwise equal role assignment that maps T to $t^{\prime}$. This hard-wired approach to temporal closure overgenerates. For example, the invalid argument in (65a) is wrongly predicted valid since temporal closure causes (65b) to entail (65c). More generally, the temporal closure principle has the effect that in order for a verbal predicate to be true, it no longer has to be true at whatever time $t$ it is formally related to, it is merely required to be true at some interval or other within that time.

a. A diplomat visited every country.

b. $\exists t . t<$ now $\wedge \exists x$.diplomat $(x) \wedge$

$\forall y \cdot \operatorname{country}(y) \rightarrow \operatorname{visit}([\operatorname{ARG} 1, x ; \operatorname{ARG} 2, y ; \mathrm{T}, t])$
a. It took John five years to learn Russian.
$\nRightarrow$ It took John ten years to learn Russian.
b. $\exists t . t<$ now $\wedge$ years $(t)=5 \wedge$ learn([ARG1, $j ;$ ARG $2, r ; \mathrm{T}, t])$
c. $\exists t . t<$ now $\wedge$ years $(t)=10 \wedge \operatorname{learn}([\mathrm{ARG} 1, j ; \mathrm{ARG} 2, r ; \mathrm{T}, t])$

Quantificational event semantics avoids the need for stipulating argument reduction and temporal closure principles. B\&C's role assignments are very similar to properties of events. For example, $g_{1}$ above corresponds to the property of being an event whose agent is John, whose theme is Bill, and which takes place at 1 pm. Note that this property could in principle apply to more than one event, for example if John kicked and slapped Bill at the same time. So in terms of event semantics, a role assignment corresponds to a set of events and not just to one event. Since B\&C's verbal projections denote sets of role assignments, we need to use an event semantics in which verbal projections denote sets of sets of events. The present system fits the bill and its derivations are quite similar to the ones in $\mathrm{B} \& \mathrm{C}$. (This is no accident, because the present system originally arose from the attempt to reconstruct $\mathrm{B} \& \mathrm{C}$ in an event-semantic framework.) For comparison, I show a B\&C-style derivation in (66) and its counterpart in (67). Here, $r, r^{\prime}$ ranges over role assignments, $f$ over sets of events, $L$ over sets of role assignments, and $V$ over sets of sets of events. Simplifying a bit, $r+[$ ARG1, $m$ ] can be read as the result of extending $f$ by a new entry that maps ARG1 to $m$.
a. $\llbracket$ Mary $\rrbracket=\lambda P . P(m)$
b. $\llbracket$ Mary:ARG1 $\rrbracket=\lambda L \lambda r . L(r+[\mathrm{ARG} 1, m])]$
c. $\llbracket[$ past $] \rrbracket=\lambda L \lambda r . L(r) \wedge r(\mathrm{~T})<$ now
d. $\llbracket$ laugh [past] $\| \lambda r^{\prime}$. $\operatorname{laugh}\left(r^{\prime}\right) \wedge r^{\prime}(\mathrm{T})<$ now
e. $\llbracket$ Mary:ARG1 laugh [past] $\rrbracket=\lambda r \cdot \operatorname{laugh}(r+[$ ARG1, $m]) \wedge r(\mathrm{~T})<$ now
f. Mary laughed iff $\exists t[\operatorname{laugh}([\mathrm{T}, t ;$ ARG1, $m]) \wedge t<$ now $]$
a. $\llbracket$ Mary $\rrbracket=\lambda P . P(m)$
b. $\llbracket[\mathrm{ag}] \mathrm{Mary} \rrbracket=\lambda V \lambda f . V(\lambda e .[f(e) \wedge \mathbf{a g}(e)=m])]$
c. $\llbracket[$ past $] \rrbracket=\lambda V \lambda f \exists t[t<$ now $\wedge V(\lambda e[f(e) \wedge \tau(e) \subseteq T t])]$
d. $\llbracket[$ closure $] \rrbracket=\lambda V \cdot V(\lambda e . \top)$ 
e. $\llbracket \operatorname{laugh} \rrbracket=\lambda f \exists e[\operatorname{laugh}(e) \wedge f(e)]$

f. $\llbracket[$ closure $][$ past $][$ ag] Mary laugh $\rrbracket=\exists t[t<\operatorname{now} \wedge \exists e[\operatorname{laugh}(e) \wedge \operatorname{ag}(e)=$ $m \wedge \tau(e) \subseteq T t]]$

In (67), I have deviated from $\mathrm{B} \& \mathrm{C}$ in distinguishing between the runtime of the event, $\tau(e)$, and the reference time interval of the sentence, $t$. The tense morpheme (67c) relates the two by temporal inclusion, which I write as $\subseteq_{T}$. This removes the need for B\&C's temporal closure principle. The tensed version of (64a) comes out as in (68); the underlined bit requires that each visit is contained within the reference interval, but does not require all visits to take place at the same time. For consistency with $\mathrm{B} \& \mathrm{C}$, I also give the tense quantifier widest scope, though this is not crucial.

$$
\begin{aligned}
& \exists t . t<\text { now } \wedge \exists x . \operatorname{diplomat}(x) \wedge \forall y \cdot \operatorname{country}(y) \rightarrow \exists e \cdot \operatorname{visit}(e) \wedge \operatorname{ag}(e)= \\
& x \wedge \operatorname{th}(e)=x \wedge \underline{\tau(e) \subseteq \subseteq_{T} t}
\end{aligned}
$$

Unlike $\mathrm{B} \& \mathrm{C}$, there is no overgeneration problem. I translate the matrix clauses of (65a) as in (69). The embedded clause is tenseless (or has present tense) instead of past tense, and therefore does not contribute $\subseteq_{T}$. The underlined parts of (70a) and (70b) block the inference in (65a).

$$
\begin{aligned}
& \text { [It took John } n \text { years to } \rrbracket=\lambda V \exists t . t<\operatorname{now} \wedge \operatorname{years}(t)=n \wedge V(\lambda e \cdot \operatorname{ag}(e)= \\
& j \wedge \tau(e)=t) \\
& \text { a. } \quad \exists t . t<\text { now } \wedge \operatorname{years}(t)=5 \wedge \exists e[\operatorname{learn}(e) \wedge \operatorname{ag}(e)=j \wedge \operatorname{th}(e)= \\
& \quad r \wedge \tau(e)=t] \\
& \text { b. } \exists t . t<\text { now } \wedge \operatorname{years}(t)=10 \wedge \exists e[\operatorname{learn}(e) \wedge \operatorname{ag}(e)=j \wedge \operatorname{th}(e)= \\
& \quad r \wedge \underline{\tau(e)=t]}
\end{aligned}
$$

There is one point in which $\mathrm{B} \& \mathrm{C}$ do afford additional formal expressivity compared to the present system. In their treatment of (71a), they model the dependency between the two temporal modifiers by letting one of them write its denotation into the value of $\mathrm{T}$, and letting the other one read it out and then replace it with its own value.

a. Last year, I visited Bill in July.

b. Last year, I lived in Rome. I visited Bill in July.

There is no way to reproduce this behavior one-to-one, as we cannot compositionally map a set of events to another one in a way that would simulate overwriting runtimes. In any case, B\&C's system is not general enough: it can only handle temporal anaphora between two temporal modifiers of the same "event" or role assignment. As suggested by (71b), a full treatment of this kind of temporal anaphora needs to be able to cross sentence boundaries (Champollion 2012). Champollion (to appear-a) provides a modular dynamic semantic treatment of temporal anaphora along the lines of continuations (Barker and Shan 2014) and monads (Charlow 2014). This treatment provides a backbone along which information can flow across sentence boundaries. A simple extension could account for cases of explicit reference to reference times like John kissed every girl. This/it took very long brought up by a reviewer as discussed in Sect. 2.

To sum up this section, verbal modification remains a strong motivation for Davidsonian event semantics. 


\title{
6 Conclusion
}

I have shown that Neo-Davidsonian event semantics does not pose a particular problem for popular compositional semantic accounts of quantification, negation and conjunction. In particular, event semantics is compatible with accounts of these phenomena that relate them to their counterparts in predicate logic, such as $\neg$ and $\wedge$. I have presented a system, quantificational event semantics, that illustrates how event semantics can be combined with standard accounts of quantification, be they syntactic or semantic. The system furthermore allows us to use a standard translation of truth-functional linguistic negation in terms of logical negation, and it is equally compatible with intersective (boolean) and collective (non-boolean) accounts of coordination. Previously, event semantics had been considered problematic for syntactic accounts of quantification and for classical accounts of negation (Beaver and Condoravdi 2007; Krifka 1989). It had also been suggested that event semantics is more amenable to collective than to intersective accounts of coordination (Lasersohn 1995).

Quantificational event semantics differs from business as usual only in that it places existential closure of the event variable inside the verb, rather than at sentence level. This then provides a simple account for the fact that the existential quantifier that binds the event variable always takes lowest possible scope, a fact which is difficult to model otherwise since it requires stipulating that quantificational arguments obligatorily take wide scope. Such a claim would be problematic especially in case of languages where quantifiers otherwise take scope in situ, such as Chinese (C.-T. J. Huang 1999; S.-F. Huang 1981). By making it possible to interpret all quantifiers in situ, quantificational event semantics combines the strengths of event semantics and type-shifting accounts of quantifiers and thus does not force the semanticist to posit either a default underlying word order or a syntactic LF-style level. It is therefore well suited for applications to languages where word order is free and quantifier scope is determined by surface order. Unlike the accounts in Beaver and Condoravdi (2007) and Eckardt (2010), it is completely standard in its assumptions and its underlying logic and should therefore be highly compatible with accounts of other phenomena formulated in the literature.

\begin{abstract}
Acknowledgments Special thanks to Cleo Condoravdi, whose paper with David Beaver (Beaver and Condoravdi 2007) provided the initial spark for this work and who provided extensive comments on early versions of the project, and to Roger Schwarzschild, who provided extremely detailed comments on this paper and its relation to some other current work of mine (Schwarzschild 2014). For many helpful comments and discussions, thanks to audiences at Stanford, NYU, at the 6th International Symposium of Cognition, Logic and Communication, at the 38th Penn Linguistics Colloquium, at the NASSLLI 2014 and ESSLLI 2014 summer schools, at the Bridges 2014 Philosophical Exchange on Inter-Theoretical Relations, and at Stony Brook University; to the Stanford semanticists, particularly Chris Potts; to the NYU semanticists, particularly Chris Barker, Simon Charlow, Philippe Schlenker, Anna Szabolcsi, and Linmin Zhang; to Jeremy Goodman, Richard Larson, Maribel Romero, and Barry Schein; to the reviewers of an earlier version of this paper, David Beaver, Michael Glanzberg, Barbara Partee, and Jurgis Skilters; to the journal editors, Graeme Forbes and Ede Zimmermann; to my managing editor, Regine Eckardt; and to the anonymous reviewers of this paper. Thanks also to Hana Filip, Larry Horn, George Lakoff and Barbara Partee for helping me track down the source of the observation in (23).
\end{abstract}

Open Access This article is distributed under the terms of the Creative Commons Attribution License which permits any use, distribution, and reproduction in any medium, provided the original author(s) and the source are credited. 


\section{References}

Barker, C. (2002). Continuations and the nature of quantification. Natural Language Semantics, 10, 211242. doi:10.1023/A:1022183511876.

Barker, C., \& Shan, C. (2008). Donkey anaphora is in-scope binding. Semantics and Pragmatics, 1, 1-46. doi:10.3765/sp.1.1.

Barker, C., \& Shan, C. (2014). Continuations and natural langauge. Oxford: Oxford University Press.

Barwise, J., \& Cooper, R. (1981). Generalized quantifiers and natural language. Linguistics and Philosophy, 4(2), 159-219. doi:10.1007/bf00350139.

Beaver, D., \& Condoravdi, C. (2007). On the logic of verbal modification. In M. Aloni, P. Dekker, \& F. Roelofsen (Eds.), Proceedings of the 16th Amsterdam Colloquium (pp. 3-9). Amsterdam: University of Amsterdam.

Beghelli, F., \& Stowell, T. (1997). Distributivity and negation: The syntax of each and every. In A. Szabolcsi (Ed.), Ways of scope taking (Vol. 65, pp. 71-107). Dordrecht: Kluwer. doi:10.1007/ 978-94-011-5814-5_3.

Bittner, M. (1994). Cross-linguistic semantics. Linguistics and Philosophy, 17, 53-108. doi:10.1007/ bf00985041.

Brasoveanu, A. (2012). Modified numerals as post-suppositions. Journal of Semantics, 30(2), 155209. doi:10.1093/jos/ffs003.

Carlson, G. N. (1977). Reference to kinds in English. Dissertation. Amherst, MA: University of Massachusetts.

Carlson, G. N. (1984). Thematic roles and their role in semantic interpretation. Linguistics, 22(3), 259280. doi:10.1515/ling.1984.22.3.259.

Carlson, G. N. (2003). Weak indefinites. In M. Coene \& Y. D’hulst (Eds.), From NP to DP (Vol. 1, pp. 195-210). Amsterdam/Philadelphia: John Benjamins.

Champollion, L. (2010a). Cumulative readings of every do not provide evidence for events and thematic roles. In M. Aloni, H. Bastiaanse, T. de Jager, \& K. Schulz (Eds.), Logic, language and meaning: Proceedings of the 17th Amsterdam Colloquium. Lecture Notes in Computer Science (Vol. 6042, pp. 213-222). Berlin: Springer. doi:10.1007/978-3-642-14287-1_22.

Champollion, L. (2010b). Parts of a whole: Distributivity as a bridge between aspect and measurement. Dissertation. Philadelphia, PA: University of Pennsylvania.

Champollion, L. (2012). Temporal dependencies: anaphora vs. movement. Poster presentation at the 35th GLOW colloquium, Potsdam, Germany. doi:10.13140/2.1.4058.2080.

Champollion, L. (2013). Man and woman: the last obstacle to boolean coordination. In M. Aloni, M. Franke, \& F. Roelofsen (Eds.), Proceedings of the 19th Amsterdam Colloquium (pp. 83-90). doi:10.13140/2.1.4779.1045.

Champollion, L. (2014a). Covert distributivity in algebraic event semantics. Under review. http://ling. auf.net/lingbuzz/002097.

Champollion, L. (2014b). Overt distributivity in algebraic event semantics. Under review. http://ling. auf.net/lingbuzz/002098.

Champollion, L. (2014c). Reply to Roger Schwarzschild on event semantics. doi:10.13140/2.1.1027. 1682. http://ling.auf.net/lingbuzz/002165.

Champollion, L. (2014d). Ten men and women got married today. Under review. http://ling.auf.net/ lingbuzz/002025.

Champollion, L. (to appear-a). Back to events: More on the logic of verbal modification. In Proceedings of the 38th Penn Linguistics Colloquium. University of Pennsylvania Working Papers in Linguistics (Vol. 21.1). http://www.ling.upenn.edu/pwpl/volumes.

Champollion, L. (to appear-b). Distributivity, collectivity and cumulativity. In L. Matthewson, C. Meier, H. Rullmann, and T. E. Zimmermann (Eds.), Wiley's companion to semantics. http://ling.auf.net/ lingbuzz/002133.

Champollion, L., \& Krifka, M. (to appear). Mereology. In P. Dekker \& M. Aloni (Eds.), Cambridge handbook of semantics. Cambridge University Press. http://ling.auf.net/lingbuzz/002099.

Champollion, L., Tauberer, J., \& Romero, M. (2007). The Penn Lambda Calculator: Pedagogical software for natural language semantics. In T. H. King \& E. Bender (Eds.), Proceedings of the Grammar Engineering Across Frameworks (GEAF) 2007 workshop. Stanford, CA: CSLI Online Publications. doi:10.13140/2.1.3255.3928. 
Charlow, S. (2014). On the semantics of exceptional scope. Dissertation. New York, NY: New York University.

Condoravdi, C. (2008). Punctual until as a scalar NPI. In K. Hanson \& S. Inkelas (Eds.), The nature of the word: Studies in honor of Paul Kiparsky. Current studies in linguistics (pp. 631-654). Cambridge, MA: MIT. doi:10.7551/mitpress/9780262083799.003.0027.

Csirmaz, A. (2006). Aspect, negation and quantifiers. In K. E. Kiss (Ed.), Event structure and the left periphery. Studies in natural language and linguistic theory (Vol. 68, pp. 225-253). Dordrecht: Springer. doi:10.1007/978-1-4020-4755-8_10.

Davidson, D. (1967). The logical form of action sentences. In N. Rescher (Ed.), The logic of decision and action (pp. 81-95). Pittsburgh, PA: University of Pittsburgh Press. doi:10.1093/0199246270. 003.0006 .

Davidson, D. (1969). The individuation of events. In Essays in honor of Carl G. Hempel: A tribute on the occasion of his sixty-fifth birthday. Synthese Library (pp. 216-234). Dordrecht: Springer. doi:10.1007/978-94-017-1466-2_11.

Dayal, V. (2011). Bare noun phrases. In K. von Heusinger, C. Maienborn, \& P. Portner (Eds.), Semantics: An international handbook of natural language meaning. Handbücher zur Sprach- und Kommunikationswissenschaft/Handbooks of Linguistics and Communication Science (HSK) (Vol. 2, Chap. 44, pp. 1109-1130). de Gruyter. doi:10.1515/9783110255072.1088.

de Swart, H. (1996). Meaning and use of not ... until. Journal of Semantics, 13(3), 221-263. doi:10. 1093/jos/13.3.221.

de Swart, H., \& Molendijk, A. (1999). Negation and the temporal structure of narrative discourse. Journal of Semantics, 16(1), 1-42. doi:10.1093/jos/16.1.1.

Diesing, M. (1992). Indefinites. Cambridge, MA: MIT.

Dowty, D. R. (1979). Word meaning and Montague grammar: The semantics of verbs and times in generative semantics and in Montague's PTQ. Studies in Linguistics and Philosophy (Vol. 7). Dordrecht: Reidel. doi:10.1007/978-94-009-9473-7.

Dowty, D. R. (1991). Thematic proto-roles and argument selection. Language, 67(3), 547-619. doi:10. 1353/lan.1991.0021.

Eckardt, R. (2010). A logic for easy linking semantics. In M. Aloni, H. Bastiaanse, T. de Jager, \& K. Schulz (Eds.), Logic, language and meaning. Lecture Notes in Computer Science (Vol. 6042, pp. 274-283). Berlin: Springer. doi:10.1007/978-3-642-14287-1_28.

Forbes, G. (2012). On some examples of Chomsky's. Prospects for Meaning, 3, 121-142. doi:10.1515/ 9783110216882.121.

Giannakidou, A. (2002). UNTIL, aspect and negation: a novel argument for two "until"s. In B. Jackson (Ed.), Proceedings of the 12th conference on Semantics and Linguistic Theory (SALT 12) (Vol. 12, pp. 84-103). http://elanguage.net/journals/salt/article/view/12.84.

Groenendijk, J., \& Stokhof, M. (1990). Dynamic Montague grammar. In L. Kálmán \& L. Pólos (Eds.), Papers from the 2nd Symposium on Logic and Language (pp. 3-48). Budapest: Akadémiai Kiadó.

Gruber, J. S. (1965). Studies in lexical relations. Dissertation. Cambridge, MA: Massachusetts Institute of Technology. http://hdl.handle.net/1721.1/13010.

Hackl, M., Koster-Hale, J., \& Varvoutis, J. (2012). Quantification and ACD: Evidence from real-time sentence processing. Journal of Semantics, 29(2), 145-206. doi:10.1093/jos/ffr009.

Heim, I., \& Kratzer, A. (1998). Semantics in generative grammar. Oxford: Blackwell.

Hendriks, H. (1993). Studied flexibility. Dissertation. Amsterdam: University of Amsterdam.

Heycock, C., \& Zamparelli, R. (2005). Friends and colleagues: Plurality, coordination, and the structure of DP. Natural Language Semantics, 13(3), 201-270. doi:10.1007/s11050-004-2442-z.

Higginbotham, J. (1983). The logic of perceptual reports: An extensional alternative to situation semantics. The Journal of Philosophy, 80(2), 100-127. doi:10.2307/2026237.

Higginbotham, J. (1999). On events in linguistic semantics. In J. Higginbotham, F. Pianesi, \& A. C. Varzi (Eds.), Speaking of events (pp. 18-52). Oxford: Oxford University Press. doi:10.1093/acprof: oso/9780199239313.003.0002.

Horn, L. (1989). A natural history of negation. Stanford, CA: CSLI Publications.

Huang, C.-T. J. (1999). Logical relations in Chinese and the theory of grammar. Outstanding Dissertations in Linguistics. London: Routledge.

Huang, S.-F. (1981). On the scope phenomena of Chinese quantifiers. Journal of Chinese Linguistics, 9(2), 226-243. 
Iatridou, S., Anagnostopoulou, E., \& Izvorski, R. (2001). Observations about the form and meaning of the Perfect. In Ken Hale: A life in language (pp. 189-238). Cambridge, MA: MIT. doi:10.1515/ 9783110902358.153.

Jackendoff, R. S. (1972). Semantic interpretation in generative grammar. Cambridge, MA: MIT.

Jacobson, P. (1999). Towards a variable-free semantics. Linguistics and Philosophy, 22(2), 117185. doi:10.1023/a:1005464228727.

Kratzer, A. (2000). The event argument and the semantics of verbs, Chap. 2. Manuscript. Amherst: University of Massachusetts, Amherst, MA. http://semanticsarchive.net/Archive/GU1NWM4Z/.

Krifka, M. (1989). Nominal reference, temporal constitution and quantification in event semantics. In R. Bartsch, J. van Benthem, \& P. van Emde Boas (Eds.), Semantics and contextual expression (pp. 75-115). Dordrecht: Foris.

Krifka, M. (1998). The origins of telicity. In S. Rothstein (Ed.), Events and grammar. Studies in Linguistics and Philosophy (Vol. 70, pp. 197-235). Dordrecht: Kluwer. doi:10.1007/978-94-011-3969-4_9.

Krifka, M. (1999). At least some determiners aren't determiners. In K. Turner (Ed.), The semantics/pragmatics interface from different points of view (pp. 257-291). Amsterdam: Elsevier.

Landman, F. (1996). Plurality. In S. Lappin (Ed.), Handbook of contemporary semantic theory (pp. 425-457). Oxford: Blackwell.

Landman, F. (2000). Events and plurality: The Jerusalem lectures. Studies in Linguistics and Philosophy (Vol. 76). Dordrecht: Kluwer. doi:10.1007/978-94-011-4359-2.

Lasersohn, P. (1995). Plurality, conjunction and events. Studies in Linguistics and Philosophy (Vol. 55). Dordrecht: Kluwer. doi:10.1007/978-94-015-8581-1.

Link, G. (1991). Plural. In A. von Stechow \& D. Wunderlich (Eds.), Semantik: Ein internationales Handbuch der zeitgenössischen Forschung/semantics: An international handbook of contemporary research. Handbücher zur Sprach- und Kommunikationswissenschaft/Handbooks of Linguistics and Communication Science (HSK) (Vol. 6, pp. 418-440). Berlin: de Gruyter. doi:10.1515/ 9783110203363. (Reprinted in Link (1998), Chap. 2, translated by the author.)

Link, G. (1998). Algebraic semantics in language and philosophy. Stanford, CA: CSLI Publications. http://standish.stanford.edu.

Marantz, A. (1984). On the nature of grammatical relations. Cambridge, MA: MIT.

May, R. (1985). Logical form: Its structure and derivation. Cambridge, MA: MIT.

Montague, R. (1970). Universal grammar. Theoria, 36(3), 373-398. doi:10.1111/j.1755-2567.1970. tb00434.x.

Montague, R. (1973). The proper treatment of quantification in ordinary English. In J. Hintikka, J. Moravcsik, \& P. Suppes (Eds.), Approaches to natural language: Proceedings of the 1970 Stanford workshop on grammar and semantics. Synthese Library (Vol. 49, pp. 221-242). Dordrecht, Netherlands: Dordrecht: Reidel. doi:10.1007/978-94-010-2506-5_10.

Parsons, T. (1990). Events in the semantics of English. Cambridge, MA: MIT.

Parsons, T. (1995). Thematic relations and arguments. Linguistic Inquiry 26(4):635-662 http://www. jstor.org/stable/4178917.

Partee, B. H. (1973). Some structural analogies between tenses and pronouns in English. The Journal of Philosophy, 70, 601-609. doi:10.2307/2025024.

Partee, B. H. (1987). Noun phrase interpretation and type-shifting principles. In J. Groenendijk, D. de Jongh, \& M. Stokhof (Eds.), Studies in discourse representation theory and the theory of generalized quantifiers (pp. 115-143). Dordrecht: Foris. doi:10.1002/9780470758335.ch15.

Partee, B. H., \& Rooth, M. (1983). Generalized conjunction and type ambiguity. In R. Bäuerle, C. Schwarze, \& A. von Stechow (Eds.), Meaning, use and interpretation of language (pp. 361-383). Berlin: de Gruyter. doi:10.1515/9783110852820.361.

Rathert, M. (2004). Textures of time. Berlin: Akademie Verlag.

Rooth, M., \& Partee, B. H. (1982). Conjunction, type ambiguity and wide scope or. In D. P. Flickinger, M. Macken, \& N. Wiegand (Eds.), Proceedings of the 1st West Coast Conference on Formal Linguistics (WCCFL 1) (pp. 353-362). Stanford, CA: CSLI Publications.

Schein, B. (1993). Plurals and events. Cambridge, MA: MIT.

Schein, B. (2002). Events and the semantic content of thematic relations. In G. Preyer \& G. Peter (Eds.), Logical form, language and semantic content: On contemporary developments in the philosophy of language and linguistics, Oxford: Oxford University Press.

Schwarzschild, R. (2014). Distributivity, negation and quantification in event semantics: Recent work by L. Champollion. Manuscript, MIT. 
Smith, S. B. (1975). Meaning and negation. The Hague: Mouton.

Szabolcsi, A. (2014). Quantification and ACD: What is the evidence from real-time processing evidence for? A response to Hackl et al. (2012). Journal of Semantics, 31(1), 135-145. doi:10.1093/jos/ ffs 025 .

von Stechow, A. (2009). Tenses in compositional semantics. In W. Klein \& P. Li (Eds.), The expression of time (pp. 129-166). Berlin: Mouton de Gruyter. doi:10.1515/9783110199031.129.

Winter, Y. (1995). Syncategorematic conjunction and structured meanings. In M. Simons \& T. Galloway (Eds.), Proceedings of the 5th conference on Semantics and Linguistic Theory (SALT 5) (pp. 387-404). http://elanguage.net/journals/salt/article/view/5.387.

Winter, Y. (2001). Flexibility principles in Boolean semantics. Cambridge, MA: MIT.

Winter, Y., \& Zwarts, J. (2011). Event semantics and Abstract Categorial Grammar. In M. Kanazawa, M. Kracht, \& H. Seki (Eds.), Proceedings of Mathematics of Language 12. Lecture Notes in Computer Science (Vol. 6878, pp. 174-191). Berlin: Springer. doi:10.1007/978-3-642-23211-4_ 11.

Zucchi, S., \& White, M. (2001). Twigs, sequences and the temporal constitution of predicates. Linguistics and Philosophy, 24(2), 187-222. doi:10.1023/a:1005690022190. 